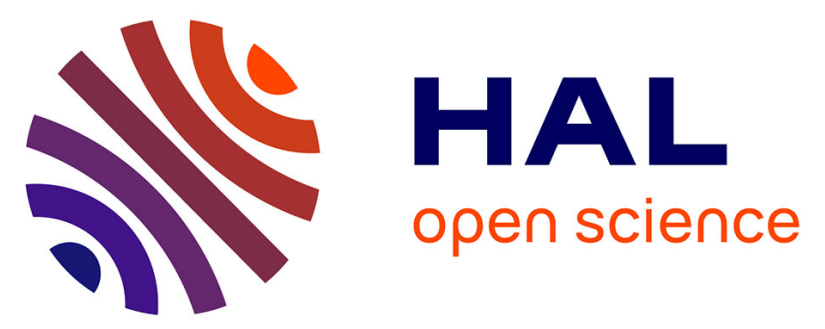

\title{
GEOV1: LAI, FAPAR essential climate variables and FCOVER global time series capitalizing over existing products. Part 2: Validation and intercomparison with reference products
}

Fernando Camacho, Jesús Cernicharo, Roselyne Lacaze, Frédéric Baret, Marie Weiss

\section{To cite this version:}

Fernando Camacho, Jesús Cernicharo, Roselyne Lacaze, Frédéric Baret, Marie Weiss. GEOV1: LAI, FAPAR essential climate variables and FCOVER global time series capitalizing over existing products. Part 2: Validation and intercomparison with reference products. Remote Sensing of Environment, 2013, 137, pp.310-329. 10.1016/j.rse.2013.02.030 . hal-01315210

\author{
HAL Id: hal-01315210 \\ https://hal.science/hal-01315210
}

Submitted on 29 May 2020

HAL is a multi-disciplinary open access archive for the deposit and dissemination of scientific research documents, whether they are published or not. The documents may come from teaching and research institutions in France or abroad, or from public or private research centers.
L'archive ouverte pluridisciplinaire HAL, est destinée au dépôt et à la diffusion de documents scientifiques de niveau recherche, publiés ou non, émanant des établissements d'enseignement et de recherche français ou étrangers, des laboratoires publics ou privés. 


\title{
GEOV1:LAI, FAPAR Essential Climate Variables and FCOVER global time series capitalizing over existing products. Part 2: Validation and intercomparison with reference products.
}

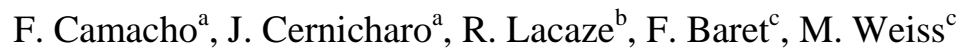

\author{
a EOLAB, Parc Científic Universitat de València, C/ Catedràtic José Beltrán, 2. 46980 \\ Paterna, Valencia, Spain \\ b HYGEOS, CesbioBpi 2108,18 avenue E. Belin, 31401 Toulouse Cedex 9, France \\ c INRA, UAPV. UMR1114, EMMAH, Domaine Saint-Paul, Site Agroparc, 84914 \\ Avignon, France \\ Corresponding author: fernando.camacho@eolab.es
}

\begin{abstract}
This paper describes the scientific validation of the first version of global biophysical products (i.e., Leaf Area Index, Fraction of Absorbed Photosynthetically Active Radiation and Fraction of Vegetation Cover), namely GEOV1, developed in the framework of the Geoland2/BioPar Core Mapping Service at $1 \mathrm{~km}$ spatial resolution and 10-days temporal frequency. The strategy follows the recommendations of the CEOS/WGCV Land Product Validation for LAI global products validation. Several criteria of performance were evaluated, including continuity, spatial and temporal consistency, dynamic range of retrievals, statistical analysis per biome type, precision and accuracy. The spatial and temporal consistency of GEOV1 products was assessed by intercomparison with reference global products (MODIS C5, CYCLOPES V3.1, GLOBCARBON V2 LAI, JRC SeaWIFS FAPAR) over a global network of homogeneous sites (BELMANIP-2) during the 2003-2005 period. The accuracy of GEOV1 was evaluated against a number of available ground reference maps. Our results show that GEOV1 products present reliable spatial distribution, smooth temporal profiles which are stable from year to year, good dynamic range with reliable magnitude for bare areas and dense forests, and optimal performances with ground-based maps. GEOV1 outperforms the quality of reference global products in most of the examined criteria, and constitutes a step forward in the development of consistent and accurate global biophysical variables within the context of the Land Monitoring Core Service of GMES.
\end{abstract}

\section{INTRODUCTION}

Delivering validated remote sensing surface biophysical products associated to quantitative uncertainties is mandatory for efficiently using this source of information. The products should show a significant level of spatial and temporal consistency for mapping or monitoring the dynamics of vegetation characteristics. Further, these biophysical variables may be integrated with other sources of information within process models. The knowledge of the uncertainties attached to these remote sensing derived products would be exploited to weigh the contribution of this source of information as compared to other possible information including prior information on model parameters and variables, climate variables or soil properties.

The Land Product Validation Sub-Group (LPV) of the Working Group Cal/Val (WGCV) of the Committee on Earth Observing Satellite (CEOS) was established to define standards guidelines and protocolsand to foster data relevant to the validation of land products, focused on the Essential Climate Variables of the Global Terrestrial Observation System (GTOS).(Justice et al., 
2000; Morisette et al., 2006). However, the validation is a difficult task for medium resolution global satellite products due to the large range of situations and variability in potential sources of errorencountered on a global basis. In addition, the mismatch between the small spatial footprintof ground observations used for independent measurement of the targeted variables and the size of the medium resolution pixels further complicates the uncertainty assessment. Comparison with in-situ measurements (i.e. direct validation) allows quantifying the accuracy of the products. The comparison with ground data is achieved by scaling up the ground measurements using a high resolution imagery (ground sampling distance-GSD- around $20 \mathrm{~m}$ ), which is later aggregated to the moderate resolution products (Morisette et al., 2006). However, the existing data sets are limited in time and space and, thus, are not representative of global conditions (Baret et al., 2006). The quantification of the spatial and temporal consistency of the products allows providing estimates of the attached precision over a larger range of situations since this do not require concurrent ground measurements. Further, intercomparison with similar satellite products (i.e. indirect validation) allows analyzing the consistency among several satellite products over a large dataset representative of global vegetation conditions and may also provide an independent way to build a community reference. Finally, benchmarking of remote sensing products is essential to identify and possibly resolve differences between products, leading to improvement in their accuracy and reliability (GCOS, 2010).

Previous validation activities of global remote sensing biophysical products showed that the seasonality of the products is generally consistent while major discrepancies are observed in terms of magnitude, which are in many situations beyond user's requirements (Camacho et al., 2006; Weiss et al., 2007; Garcia-Haro et al., 2008; Garrigues et al., 2008a; Ganguly et al., 2008; McCallum et al., 2010; Fang et al., 2012). These may be explained by the assumptions embedded in the retrieval algorithm and product definition, the sensor characteristics (spectral function, point spread function) and processing chain including radiometric calibration, geometrical correction, projection, water bodies and snow and cloud detection, atmospheric correction or directional normalization. Different authors found that CYCLOPES v3.1 (Baret et al., 2007) and MODIS c5 (Knyazikhin et al.,1998) LAI and FAPAR products are the more consistent global products (Weiss et al., 2007; Garrigues et al., 2008a; McCallum et al., 2010). Both products have been widely validated, reaching the Stage 2 validation according to the CEOS hierarchical four-stage validation approach, and some authors have initiated the Stage 3 validation showing uncertainties in LAI around \pm 1.0 (Fang et al., 2012). In summary, validation efforts showed that CYCLOPES products were found reliable for the lower vegetation values whereas an early saturation was observed in LAI (Weiss et al., 2007) and FCOVER (Camacho et al., 2006) products. Conversely, MODIS LAI/FAPAR products were found more reliable for the higher vegetation values, showing however an overestimation of the lower FAPAR values (McCallum et al., 2010; Camacho et al., 2010). Moreover, MODIS displayed noisy temporal retrievals and unrealistically strong temporal variations over some regions (Kobayashi et al., 2010).

The GEOV1 LAI, FAPAR and FCOVER products are derived from CYCLOPES v3.1 and MODIS c5 biophysical products based on their associated validation results (see details in the companion paper, Baret et al., 2012).The aim was to capitalize on the previous efforts spent on their development and validation, taking benefit of the better performances of each product while reducing their main drawbacks. GEOV1 products have been developed within the FP7 geoland2 project (http://www.gmes-geoland.info) aiming to implement the GMES (Global Monitoring for Environment and Security) Land Monitoring Services. One component of the project, the BioPar Core Mapping Service, is setting-up an operational system, fully validated, providing biophysical products at a range of scales relevant to a number of applications including forest and natural resources management, agri-environmental indicators, crop monitoring and food security, or carbon cycle diagnostic and prognostic description. All these applications require long-term global time series of vegetation variables (LAI, FAPAR, FCOVER and albedo) with typical target accuracy and stability (i.e., the extent to which accuracy remains constant with time) around 0.5 and 0.05 for LAI and FAPAR respectively 
(GCOS, 2006). For the FCOVER, the same accuracy and precision as for the FAPAR are expected.

In this context, the primary objectives of this paper are: (1) to validate the GEOV1 LAI, FAPAR and FCOVER biophysical products (Baret et al., 2012) by direct comparison with ground measurements processed according to CEOS/WGCV LPV recommendations(Morisette et al., 2006) that were mainly compiled in Garrigues et al. (2008a), (2) to evaluate the spatial and temporal consistency of the GEOV1 products over large domains by intercomparison with reference products, and (3) to assess the added-value of GEOV1 regarding its two precursor products (CYCLOPES v3.1 and MODIS C5). For the intercomparison two independent references were used: The GLOBCARBON v2 LAI (Deng et al., 2006) and the JRC Sea WiFS FAPAR (Gobron et al., 2006). This was partly achieved over the BELMANIP-2 (Benchmark Land Multisite Analysis and Intercomparison of Products) network of sites that aim to sample in a representative way the global variability of vegetation types (Baret et al., 2006) for the period 2003-2005.

The next section of this paper briefly describes each remote sensing biophysical product evaluated in this work, and the validation procedure is presented in section 3 . The results are discussed in section 4 , before giving conclusions in the last section.

\section{REMOTE SENSING VEGETATION PRODUCTS}

In this section, we provide the main characteristics of the global remote sensing vegetation products investigated in this work. A summary with their main characteristics can be found in Table 1.

Table 1: Characteristics of the global remote sensing products under study. GSD, ANN, LUT, VI and RTM stands for "Ground Sampling distance", "Artificial Neural Network", "Look up table", "Vegetation Index", and "Radiative Transfer Model”, respectively.

\begin{tabular}{|c|c|c|c|c|c|c|c|}
\hline Product & Sensor & GSD & Frequency & Algorithm & Parameterization & Clumping & Reference \\
\hline CYCLOPES V3.1 & VGT/SPOT & $1 \mathrm{~km}$ & 10-days & $\begin{array}{c}\text { Inversion RTM } \\
\text { 1D (ANN) }\end{array}$ & Global & Landscape & $\begin{array}{l}\text { Baret et al, } \\
\text { (2007) }\end{array}$ \\
\hline MODIS C5 & MODIS/TERRA & $1 \mathrm{~km}$ & 8-days & $\begin{array}{c}\text { Inversion RTM } \\
\text { 3D (LUT) }\end{array}$ & 8-biomes (MODIS) & $\begin{array}{l}\text { Plant, canopy \& } \\
\text { landscape }\end{array}$ & $\begin{array}{c}\text { Knyazikhin et } \\
\text { al.,(1998) }\end{array}$ \\
\hline $\begin{array}{c}\text { GLOBCARBON } \\
\text { V2 }\end{array}$ & AATSR+VGT & $1 \mathrm{~km}$ & monthly & $\begin{array}{l}\text { VI-LAI } \\
\text { relationship } \\
\text { (RTM 3D) }\end{array}$ & GLC-2000 & Plant \& canopy & $\begin{array}{l}\text { Deng et al., } \\
\text { (2006) }\end{array}$ \\
\hline JRC-FAPAR & SeaWIFS & $2.17 \mathrm{~km}$ & daily & $\begin{array}{l}\text { VI-FAPAR } \\
\text { optimization } \\
\text { (RTM 1D) }\end{array}$ & Global & No & $\begin{array}{c}\text { Gobron et al., } \\
\quad(2006)\end{array}$ \\
\hline GEOV1 & VGT/SPOT & $1 \mathrm{~km}$ & 10-days & $\begin{array}{l}\text { ANN trained } \\
\text { with CYC and } \\
\text { MOD products }\end{array}$ & Global & $\begin{array}{l}\text { Weighted of } \\
\text { CYC and MOD }\end{array}$ & $\begin{array}{l}\text { Baret et } \\
\text { al.,(2012) }\end{array}$ \\
\hline
\end{tabular}

\subsection{CYCLOPES}

The Cyclopes Version 3.1 (http://postel.mediasfrance.org) is produced from the SPOT/VEGETATION sensor at $1 / 112^{\circ}$ (about $1 \mathrm{~km}$ at equator) spatial sampling distanceand a 10-days temporal sampling, in a Plate Carrée projection, for the period 1999-2007 (Baret et al., 2007). The algorithm uses as input the red, near-infrared and short-wave infrared snow and cloud free reflectances (Hagolle et al., 2004) normalized to a standard geometry. The normalization is performed by inversion of a BRDF model (Roujean et al., 1992) over data accumulated during a 30-days compositing period. Products are estimated using a neural 
network trained from a coupled leaf (PROSPECT model; Jacquemond and Baret, 1990) and canopy one-dimensional radiative transfer model (SAIL model; Verhoef, 1984) simulations without using any parameterization as a function of the biome. Clumping, i.e. heterogeneity in leaf area density distribution in the canopy volume may occur at several scales as described in Garrigues et al., 2008. Clumping at the plant and canopy scale is not represented in the algorithm, but the landscape clumping is represented by considering mixed pixels made of a fraction of pure vegetation and a complement fraction of pure bare soil. Therefore, the LAI corresponds to an effective LAI rather than an actual LAI. Further, all the green elements in the canopy are considered, including stems when green and green background. The FAPAR is defined as the instantaneous black-sky FAPAR at 10:00h, referring only to the green elements. The FCOVER is defined as the complementary to the gap fraction in the nadir view, considering also only the green elements. The CYCLOPES products are provided with the corresponding error estimate and a quality flag (only good quality outputs were used for this study).

Several authors assessed the merit of the CYCLOPES products by comparison with available ground truth maps and intercomparison with remote sensing products at global scale (Weiss et al., 2007; Garrigues et al., 2008a; Ganguly et al., 2008; Fang et al., 2012) or over different regions (Camacho et al., 2006; Garcia-Haro et al., 2008; Verger et al., 2009a; McCallum et al., 2010). An early saturation of the LAI associated to the assumption of the RT model and the saturation of the signal, and an unreliable small dynamic range for the FCOVER with maximum values around 0.7 were the main limitations reported for the CYCLOPES V3.1 products.

\subsection{MODIS}

Terra MODIS LAI/FPAR (MOD15A2) Collection 5, available since 2000 (https://lpdaac.usgs.gov/lpdaac/products/) is produced at 1 kmground sampling distance and 8 days frequencyover a sinusoidal grid (Yang et al., 2006a; Myneni et al., 2002). The main algorithm is based on LUTs simulated from a three-dimensional radiative transfer model (Knyazhikin et al., 1998). The MODIS red and NIR atmospherically corrected reflectances (Vermote et al., 1997) and the corresponding illumination-view geometry are used as input of the LUTs. The output is the mean LAI/FAPAR computed over the set of acceptable LUT elements for which simulated and measured MODIS surface reflectances are within specified uncertainties. When the main algorithm fails, a backup solution based on LAI/FAPAR-NDVI relationships is used. In Collection 5, parameters of both main and backup algorithm are defined for 8 vegetation types, and a new stochastic RT model was used to better represent canopy structure and the spatial heterogeneity intrinsic to woody biomes. The parameters of the new LUTs were selected to minimize anomalies in LAI retrievals (LAI overestimation and algorithm failure over medium/dense vegetation) and inconsistency between LAI and FPAR retrievals (i.e., correct LAI with FAPAR being overestimated over sparse vegetation) noted in a former version of the product. The model takes into account the clumping at plant and canopy levels through the model (Knyazikhin et al., 1998). Therefore, the LAI corresponds to a true LAI over all the biomes except needle forest where shoot clumping was not accounted for. The FAPAR is defined as the instantaneous black-sky at the time of the TERRA overpass (10:30 h). LAI and FAPAR are produced daily, and then the LAI value corresponding to the maximum FAPAR is selected over the eight-day compositing period. The MODIS estimates are provided with a standard deviation and a quality flag. However, the back-up solution is mainly triggered when the surface reflectance is highly uncertain due to residual clouds or snow contaminated reflectance (Yang et al., 2006a), leading to lower accuracy products. Consequently only 
solutions from the main algorithm were used in this validation exercise. Besides, according to the quality flag information, land pixels where the cloud status is not clear or where the presence of cirrus is detected were discarded. Note that no data is retrieved over bare areas and very sparsely vegetated areas, perennial ice and snow, permanent wetlands, urban and water bodies.

Many different validation studies of MODIS LAI/FAPAR products can be found in the literature for previous versions (Tan et al., 2005; Abuelgasin et al., 2006; Cohen et al., 2006; Steinberg et al., 2006; Pisek and Chen, 2007; Weiss et al., 2007; Garrigues et al., 2008a). However, the most recent collection 5 has not been widely validated yet. A few studies suggest that MODIS LAI c5 shows improved temporal LAI dynamic over forest sites (Verger et al., 2009a; De Kauwe et al., 2011, Fang et al., 2012). The main drawbacks of MODIS LAI/FAPAR c5 areitsunrealistically strong temporal variability (e.g., Kobayashi et al., 2010) and thesystematic overestimation of FAPAR retrievals over sparsely vegetated areas (Camacho et al., 2010).

\subsection{GLOBCARBON}

The GLOBCARBON LAI Version 2(http://geofront.vgt.vito.be/geosuccess/) is estimated for the period 1998-2007 from the combination of observations from two sensors: SPOT/VEGETATION and ENVISAT/AATSR (ATSR-2 for the 1998-2002 period). Deng et al., (2006) produced an algorithm for global retrieval of LAI, which is based on a geometrical optical model (Four Scale; Chen and Leblanc, 1997) with a multiple scattering scheme (Chen and Leblanc, 2001) and LAI algorithms previously derived for Canada. The algorithm uses red, near-infrared and shortwave infrared bands which are combined into Simple Ratio (SR) and Reduced Simple Ratio (RSR) for effective LAI retrieval. The clumping index derived by Chen et al., (2005) from POLDER multi-angular observations as a function of the Global Land Cover (GLC) 2000 map (Bartholomé and Belward, 2005) is applied to account for the clumping at plant and canopy scales. Individual estimates of LAI are produced for all the valid pixels from each sensor (atmospherically corrected, cloud-free and snow-free) and then the median is computed at a 10-day time step from all the available values from all the sensors. The 10-day values are subjected to a smoothing and interpolation procedure (Chen et al., 2006a). The smoothed LAI observations are then averaged over one month period and aggregated to a $1 / 112^{\circ}$ spatial sampling grid in a Plate Carrée projection. A flag value indicates when no LAI estimate is computed, i.e., no clear observation or for several GLC 2000 classes (bare areas, snow and ice, etc). Validation and intercomparison studies showed a systematic underestimates of GLOBCARBON LAI V1 over croplands and shrublands, as well as lack oftemporal consistency over evergreen broadleaf forest sites (Garrigues et al., 2008a).

\subsection{JRC SEAWIFS FAPAR}

The Joint Research Center (JRC) FAPAR product (http://fapar.jrc.ec.europa.eu/), is estimated for the period 1997-2006 from the Sea-viewing Wide Field-of-view Sensor (SeaWiFS) onboard Orbview-2. The products have been remapped into a global sinusoidal projection at $2.17 \mathrm{~km}$ and are generated on a daily, 10-days and monthly basis. The FAPAR algorithm is based on the concept of an optimized vegetation index proposed by Verstraete and Pinty (1996) and then applied to multiple sensors including the Medium Resolution Imaging Spectrometer (MERIS) (Gobron et al., 1999; Govaerts et al., 1999) and SeaWiFS (Gobron et al., 2006). 
The FAPAR is estimated in a two-step procedure.The spectral bidirectional reflectance factor in the red and NIR regions are first rectified to correct from atmospheric effects based on relationships with the blue spectral band (Gobron et al., 1999; Govaerts et al., 1999) and then directionally normalized. Then, the coefficients of the index are adjusted over a synthetic data base to best estimate the instantaneousFAPAR under direct illumination at the time of acquisition(Gobron et al., 2002).The data base is made of simulations using a one-dimensional radiation transfer model in the canopy coupled with an atmosphere model (Gobron et al., 2000) over a range of canopy, atmosphere and observational configurations. Although 3D structure of the canopy is not accounted for, the algorithm was found robust with respect to specific perturbations introduced by three-dimensional effects (Gobron et al., 2000).

Validation results of the SeaWiFS FAPAR product against ground based estimates over several locations representing different radiative transfer regimes were discussed by Gobron et al., (2006). The FAPAR products appeared biased low with respect to the ground-based estimations especially under conditions where the structural effects become significant and/or the contribution of the woody elements of the canopy to the interception process is not negligible, showing a good representation of the seasonal cycles. Furthermore, intercomparison exercises with other FAPAR satellite products derived from MODIS, MERIS, MSG or GLOBCARBON using different algorithms (García-Haro et al., 2008; McCallum et al., 2010), demonstrate a systematic underestimation of the JRC FAPAR which was very significant (up to 0.3) for forest sites. These discrepancies should be explained due to the specific distribution of input variables used to calibrate the relationshipas well as a slightly later time of observation by SEAWIFS corresponding to lower solar zenith angles.

\subsection{BIOPAR GEOV1}

Geoland2/BioPar Version 1 (GEOV1) products are derived from the SPOT/VEGETATION sensor data at $1 / 112^{\circ}$ (about $1 \mathrm{~km}$ at the equator) spatial sampling intervaland at 10 days frequency, in a Plate Carrée projection (example on Figure 1).The retrieval methodology is described in the companion paper (Baret et al., 2012). It relies on neural networks trained to generatethe "best estimates" of LAI, FAPAR, and FCOVER obtained by fusing and scaling MODIS and CYCLOPES products. The input data are SPOT/VEGETATION top of canopy directionally normalized reflectances that are derived using almost the same CYCLOPES processing chain (Hagolle et al. 2004). The only difference is in the compositing temporal weighting function that was adapted to a near real time production (i.e., the higher weight was placed in the last observations). Thus, GEOV1 is expected to be highly correlated to CYCV3.1 while displaying systematically larger values for dense canopies thanks to the contribution of MODIS products in the training process. The LAI is close to the actual value since clumping affects mainly canopies with the higher LAI where MODIS contribution is dominant. The FAPAR corresponds to the instantaneous black-sky around 10:15h, which is a close approximation of the daily integrated black-sky FAPAR value. Note that conversely to MODIS and similarly to CYCLOPES, no biome classification is required to run the GEOV1 algorithm. The GEOV1 products are disseminated in open access through the geoland2 web portal (http://www.geoland2.eu). 


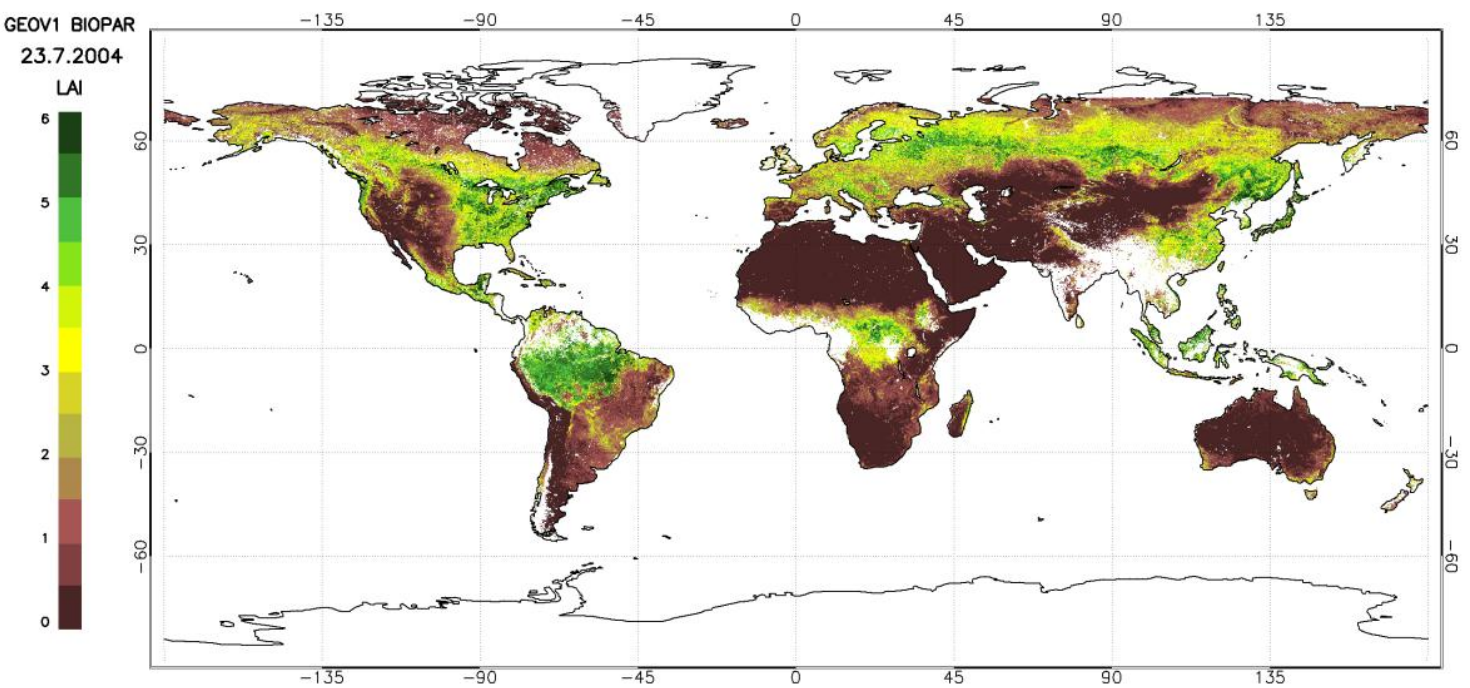

Figure 1:GEOV1 LAI global map corresponding to the $23^{\text {rd }}$ of July of 2004.

\section{METHODOLOGY}

The validation procedure was defined to be consistent with the best practices proposed by CEOS WGCV LPV subgroup (Morissette et al., 2006; Garrigues et al., 2008a, Weiss et al., 2007), taking also into account the main requirements expressed by the users (Lacaze et al., 2009). A series of metrics and qualitative checks were completed to assess the continuity, consistency and precision as well as accuracy of the GEOV1 products in comparison with the performances of the other existing global products (CYCLOPES LAI/FAPAR/FCOVERv3.1, MODIS LAI/FAPAR c5, GLOBCARBON LAI v2 and JRC SeaWIFS FAPAR). Methods, sampling strategy and metrics are presented below for each of the criterions considered.

Note that, except for the production of maps and the computation of the fraction of missing data, for which the original projection of the products was kept, the spatial sampling was adaptedto get similar spatial support across all the products investigated when performing the intercomparison over site extracts. The products were first resampled over a common Plate Carrée projection over a $1 / 112^{\circ}$ (about $1 \mathrm{~km}$ at equator) spatial sampling grid. Further, to reduce co-registration errors between products and inconsistencies associated to differences in the point spread function of the reprojected products, the average value of the valid observations computed over the $3 \times 3$ pixels as resampled over the common Plate Carrée grid was considered if more than 5 out of the 9 pixels were valid (Weiss et al., 2007). This $3 \times 3$ pixels spatial support used to intercompare products will be later called minimum consistent spatial support (MCSS).

\subsection{SPATIAL AND TEMPORAL CONTINUITY}

It represents the fraction and distribution in space and time of the missing data (gaps), mainly due to cloud or snow contamination, poor atmospheric conditions or technical problems during the acquisition of the images. This criterion has been identified as very important by applications using the products either in a descriptive mode or when forcing process models. The fraction of missing datawas computed as a function of time and latitude. All the data available during the 2003-2005 period were used with their original spatial and temporal sampling .Note that bare areas are not included in the analysis since MODIS and GLOBCARBON does only provide a default value over these land classes. Moreover, the 
distribution of the temporal length of the gaps was also evaluated in orderto better understand the impact of the missing valuesfor monitoring temporal variations.

\subsection{SPATIAL CONSISTENCY}

The globalmaps of products were generated and analyzed to investigate possible patterns specific to a given product as well to check the spatial consistency through visual analysis (artifacts corresponding to tiles, stripes, presence of outliers). To investigate the spatial correlations of product differences, maps of the annual mean difference between products (mean bias error, B) and maps of the annual root mean square error (RMSE) were computed over each MCSSfor the two years period. To better compare the maps, a common temporal support period (CTSP) should be considered. The lower temporal sampling amongst the several products was selected: the monthly temporal sampling of GLOBCARBON.For GEOV1 and CYCV31 products, the central dekad of each month was considered. For MODIS products, the average value of best quality pixels of the closest bracketing images around the $15^{\text {th }}$ of each month was used. For JRC-FAPAR daily product, a monthly average was computed from daily observations.

\subsection{TEMPORAL CONSISTENCY}

Temporal profiles observed over asmall sample of sites taken from the main biome classes were first analyzed to qualitatively assess the main differences between the several products considered, with emphasis on areas showing the larger discrepancies. The smoothness as a measure of the short time stability is a major component of the temporal consistency. As a matter of fact, the temporal smoothness is expected for these LAI, FAPAR and FCOVER variables that change through incremental processes (except in the case of disturbance). It was characterized as suggested by (Weiss et al., 2007): for three consecutive product dates,

in the times series, the absolute value of the difference between the center, , and the average value of the products corresponding to the two adjacent dates, and , was computed:

\subsection{BULK STATISTICAL ANALYSIS}

Because the spatial and temporal consistency evaluation presented before rely on a limited spatial domain (few sites for the temporal consistency) or a temporal period (few dates for the spatial consistency) a more comprehensive analysis is required. It is conducted over the whole common time period available (2003-2005) and for a globally representative set of sites.The BELMANIP-2 network of sites designed to represent globally the variability of land surface types was used here(see Figure 2 in Baret et al., 2012). It is an improved version of the original BELMANIP sites (Baret et al., 2006). To allow comparison between the products, the same temporal (month) and spatial (3x3 pixels) supports were used. 
The distribution of products values is then generated in the form of PDFs (Probablity Density Function). The consistency between GEOV1 and the other products is further quantified based on metrics associated to the scatterplots between pairs of products (i.e., correlation, bias, root mean square error). These analyses are achieved per aggregated land cover class based on the 7 generic classes derived from the GLC-2000 classification (Bartholomé and Belward, 2005): Broadleaf Evergreen Forest (BEF), Broadleaf Deciduous Forest (BDF), Needle-leaf Forest (NLF), Shrublands (S), Herbaceous (H), Cultivated (C), Sparse and Bare areas (SBA).

\subsection{DIRECT VALIDATION}

The accuracy of satellite products was computed usinga ground reference dataset representative of an area of approximately $3 \times 3$ pixels that allows limiting the effects of point spread function and geometric accuracy. Here, due to the small number of concomitant space and ground measurements during the 2003-2005 period, the whole time series of the biophysical products under study was considered to increase the number of validation samples. The product date the closest to the date of ground measurement was considered for each site.

\subsubsection{The available data}

The in-situ dataset was processed according tothe guidelines defined by the CEOS/WGCV LPV subgroup (Morisette et al., 2006). The "state of the art" direct validation approach consists in using high spatial resolution imagery to scale the local ground measurements up to the $3 \times 3$ pixel area of the site. An empirical "transfer function" between high spatial resolution radiometric signal and the biophysical measurements is established using a representative number of Elementary Sampling Units (ESUs) (e.g., Cohen et al, 1999, Martinez et al., 2009). Empirical transfer functions range from simple average (i.e. SAFARI-2000 campaign (Privette et al., 2004)), relationship with vegetation indices or more complex functions (http://w3.avignon.inra.fr/valeri). It is then applied to all the high spatial resolution pixels of the whole site. The resulting high spatial resolution map of the considered biophysical variable is finally averaged over the $3 \times 3$ medium resolution pixels (Garrigues et al., 2008a). Most of the reference biophysical variables derived from ground measurements were resulting from international initiatives such as VALERI (http://w3.avignon.inra.fr/valeri), BigFoot (Cohen et al., 2006), NASA (SAFARI-2000, Privette et al., 2004; Camacho and Torralba, 2010), Boston University (Yang et al., 2006b), Canada Centre for Remote Sensing (Abuelgasin et al., 2006), U.S. Environmental Protection Agency (Iiames et al., 2004) and ESA (Camacho and Lanjeri, 2008).

\subsubsection{Improving the consistency of reference ground measurements}

This compilation of available scaled-up ground measurements of the biophysical variables reveals some variation in the indirect ground measurement methods used for LAI, FAPAR and FCOVER assessment. This was carefully screened out to provide the best consistency within these reference values.

Several sources of uncertainties are primarily affecting ground estimates from the transmittance measurements achieved with theoretical devices such as LAI2000, TRAC or digital hemispherical photography (Gower et al., 1999; Weiss et al., 2004, Garrigues et al., 2008b). 
(i) no distinction is made between photosynthetically active tissues and other plant elements such as branches, stems, trunks, and senescent leaves. This may result in overestimates of the biophysical variables relative to the green elements (Chen et al., 2006b), although this impact might be moderate for most canopies since measurements were generally taken close to the maximum vegetation development. Further, this problem is partly reduced using digital hemispherical photographs taken above the canopies, green leaves being generally at the top of canopy, masking most of the non-green elements.

(ii) in the case of forests, a total of 30 sites where the understory was not measured,mostly over Canadian Forest (Abuelgasin et al., 2006), were discarded in this study. Indeed, not measuring the understory may result in significant discrepancies with the satellite products corresponding to both the overstory and understory layers (Wang et al., 2004). We have verified that GEOV1 provides systematically higher LAI values over these sites.

(iii) optical instruments provide straightforward estimates of the effective LAI, i.e. assuming a random spatial distribution of leaves. However, the effective LAI may differ significantly from the true LAI (Chen and Cihlar, 1995) particularly in the case of forests with high LAI values. Deviation from the random distribution ideal case is measured by the clumping index that can be estimated using the TRAC instrument (Chen and Cihlar, 1995) or from digital hemispherical photography (Demarez et al., 2008). However, this correction is not perfect because the clumping index varies with the zenith angle (Chen, 1996; Law et al. 2001) as well as with the size of the processing cells (Demarez et al., 2008). Note however that the clumping at the shoot scale is generally not accounted for in the ground measurements, consistently with the satellite derived products definition used.

(iv) FAPAR estimated from optical measurements assumes black leaves in the PAR domain because of the strong absorption by the photosynthetic pigments. This hypothesis however introduces systematic overestimation regarding the actual FAPAR with a difference that can reach0.05 to 0.1 in the case of bright background and sparse canopies (Gobron et al., 2006).

(v) Finally, other sources of errors include performance of instruments depending on illumination conditions, suboptimal sampling (Garrigues et al., 2008b; Verger et al., 2009b) and saturation of optical signal in dense canopies.

The overall uncertainty associated to each ground reference maps is not documented. Martinez et al., (2009) reported that the uncertainty of a ground reference effective LAI map associated to the use of different instruments, sampling strategy, number of observations, and band combination used in the transfer function was around 0.5 LAI units in a cropland site. This indicates that most of the random errors cancel out with the up-scaling approach leaving only the measurement bias, in agreement with Butson and Fernandes, (2004). For LAI maps corrected for clumping (except shoot clumping) and non-green elements an absolute uncertainty smaller than 1 LAI unit is expected for most of the sites (Fernandes et al., 2003). For FAPAR and FCOVER maps, the uncertainty is expected to be around 0.1.

Detailed inspection of the available data sets shows in some cases inconsistencies between LAI, FAPAR and FCOVER retrievals. The corresponding sites were discarded (Table 2). Further, the clumping index estimation was found unreliable on few VALERI sites, and these true LAI values were also discarded, in addition to those sites were canopy understory was not measured, resulting in a limited set of sites with true LAI values. A total of 41 sites (30 withLAI values) were finally available with some of them sampled several times, providing a total of 49 ground 
LAI measurements, and up to 66 available ground maps for FCOVER (Table 2). Note that most of the sites are located over Europe, Africa and North America.

Table 2: Characteristics of the validation sites (total 32) and associated ground biophysical maps $^{(*)}$

(*) "Lat","Lon","LC", " $\Omega$ ", "Meth" and "Ref" stands for "latitude", "longitude", "land cover", "clumping", "method" and "reference". In the column "LC", BEF, BDF, NLF, S, H, C and SBA stands for Broadleaf Evergreen Forest, Broadleaf Deciduous Forest, Needle-leaf Forest, Shrublands, Herbaceous, Cultivated, and Sparse and Bare areas, respectively. When multiple temporal data is available during the same year over the same site, the column of biophysical parameter provides the range of variation of the measured variable. In the column "Method", the numbers refers to 1: destructive sampling,2: LAI-2000, 3:digital hemispherical photos, 4: TRAC, 5: AccuPAR, and 6: allometry. The column "Ref" indicates the validation initiative and the associated reference. The numbers refers to 1: BigFoot (Cohen et al., 2006), 2: CCRS (Abuelgasim et al., 2006), 3: VALERI (w3.avignon.inra.frlvaleri), 4: SMOS (Camacho and Lanjeri, 2008), 5: SAFARI-2000 (Privette et al., 2004; Camacho and Torralba, 2010), 6: U.S. Environmental Protection Agency (liames et al., 2004). More information and full list of validation sites can be found on the CEOS cal/val site (http://calvalportal.ceos.org/cvp/web/olive/descriptions). The ground values identified by the asterisk were not used. 


\section{RESULTS}

\subsection{SPATIAL AND TEMPORAL CONTINUITY}

GEOV1 shows spatial and temporal distribution of missing data (Figure 2), very similar to that of CYCV31 as expected since both products are based on the same CYCLOPES preprocessed SPOT/VGT data (Hagolle et al., 2004). Both products present the higher percentage of missing values at high latitudes in the northern hemisphere, with a wide variability as a function of the period of the year, mainly due to snow coverage changes along the year as well as increase observations under dark conditions particularly above the polar circle in winter. The equatorial region presents also a large fraction of gaps (up to 50\%) as a consequence of the higher cloudiness.The length of the missing values, evaluated over BELMANIP-2 sites, shows also very similar distributions for GEOV1 and CYCV31. Around 50\% of the gaps are shorter than 30 days.

On the other hand, MODC5 main algorithm retrievals present the largest fraction of missing values in the equatorial area with values higher than $60 \%$ in the period January to March, quite similar to the results obtained in October-December period. In April-Jun and Jul-Sep corresponding to theaustral winter, the fraction of missing values is also very large beyond $40^{\circ}$ latitude south.Conversely to VEGETATION based products (CYCV31, GEOV1, GLOV2), the fraction of missing data surprisingly decreases with latitude for latitudes higher than that of the polar circle $\left(67^{\circ}\right)$.

The length of the gaps in the MODC5 product is the lowest (Figure 3), with around 60\% of gaps corresponding to one missing observation (8-days) and up to $75 \%$ of gaps within 16-days, which facilitates the reconstruction of the temporal curve. Finally, GLOV2 displaysa similar amount of gaps in the northern hemisphere as a consequence of the snow cover and cloudiness, but the combination of SPOT and ENVISAT observations provides a higher spatial continuity in the equatorial region and at high latitudes over the south hemisphere than the other products. Conversely, the length of the missing data is the largest due to the monthly frequency of the GLOV2 product. The spatial continuity of observations from polar orbiting satellite is one of the main drawbacks of these products, in contrast to products derived from geostationary sensors such as the Land-SAF MSG-based products (Camacho et al., 2010) which in turns are limited in its spatial coverage. 
Version définitive du manuscrit publiée dans / Final version of the manuscript published in :

Remote Sensing of Environment (2013), Vol. 137, p. 310-329, DOI: 10.1016/j.rse.2013.02.030

Journal homepage: www.elsevier.com/locate/rse
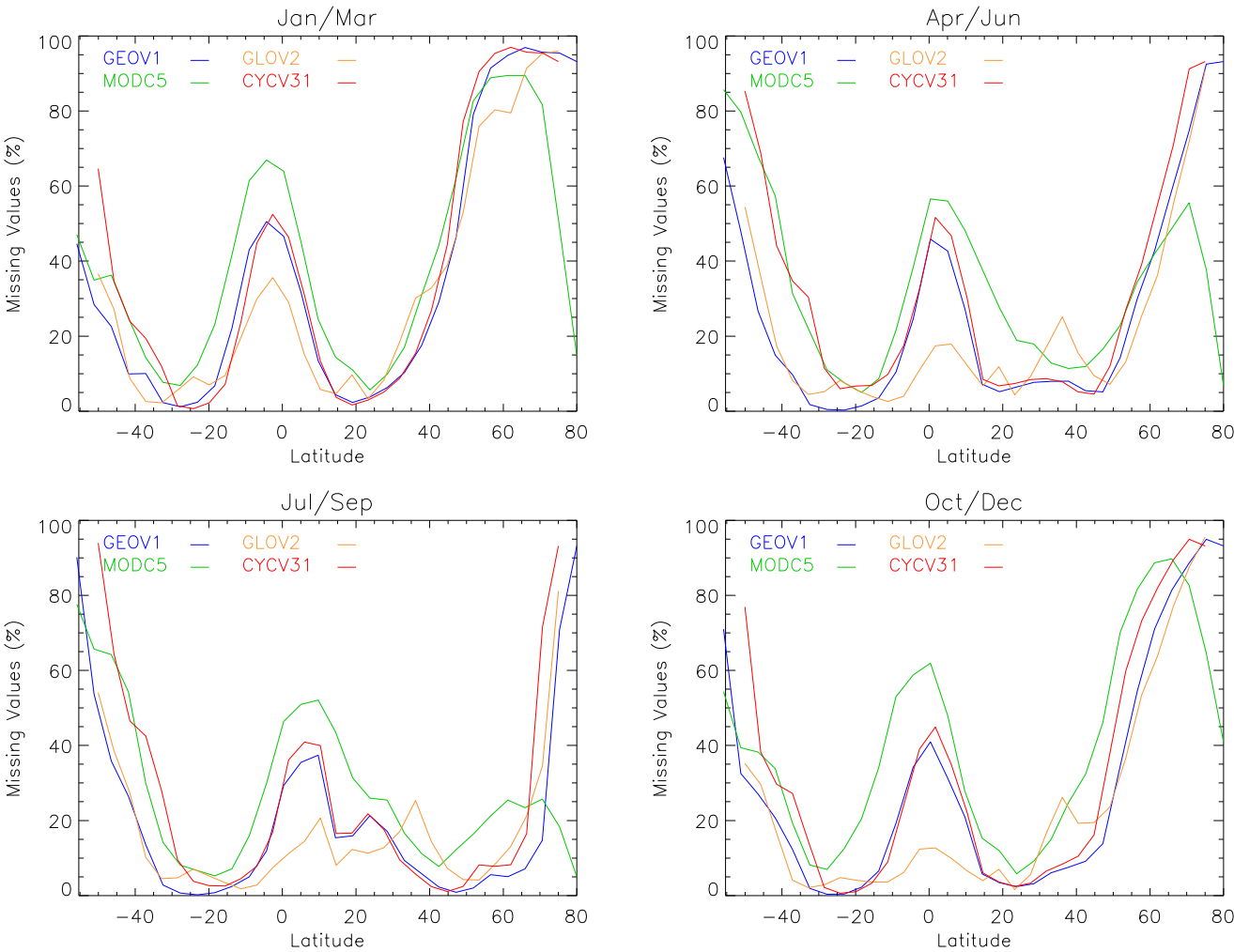

Figure 2: Percentage of missing values over land pixels as a function of latitude and period of the year for GEOV1, CYCV31, MODC5 and GLOV2 products. Bare areas are not considered.

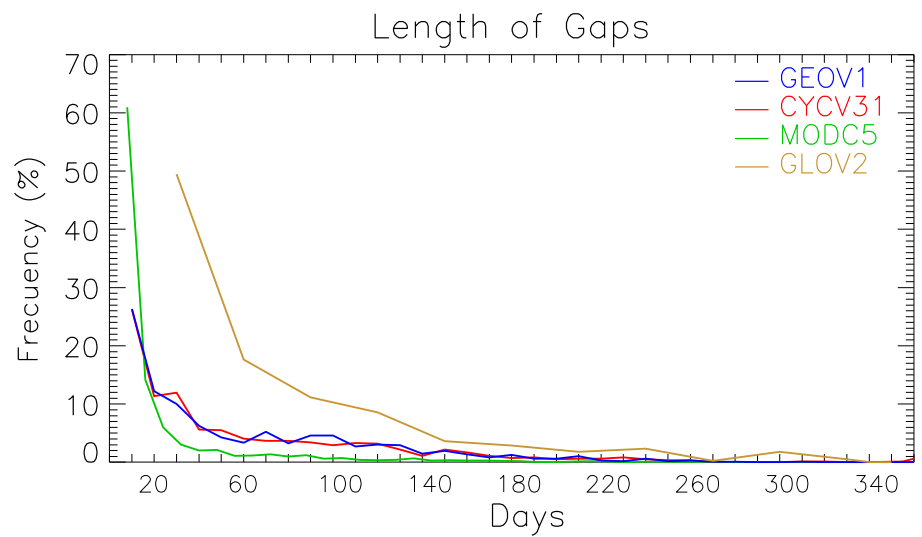

Figure 3: Distribution of the temporal length of the missing values over BELMANIP-2 sites during the period 2003-2005 for GEOV1, CYCV31, MODC5 and GLOV2 products.

\subsection{SPATIAL CONSISTENCY}

Annual mean difference maps between GEOV1 and CYCV31 display the expected systematic trend: GEOV1 shows systematically higher values over the globe, with larger differences over the dense forests. The maps are not shown here for the sake of brevity but it can be found in Camacho and Cernicharo (2010). Annual mean LAI and FAPAR difference maps between GEOV1 and MODC5 products for the two years period are presented here. For the LAI product (Figure 4-a), the grey area represents \pm 0.5 LAI differences, which constitutes $74.3 \%$ of the total 
global vegetated pixels. Systematic underestimation of GEOV1 retrievals typically around -1 LAI units are observed over broadleaf forest (e.g. Amazon rainforest, Congo rainforest), depicting a clear correlation with the MODIS biome map (Figure 4-c). Conversely, GEOV1 provides higher values over different regions around the world. A visual inspection allows identifying high spatial correlation of the product differences over Broadleaf Crop regions (e.g. USA, Ukraine). Largest deviations are however observed over Needle-leaf Forest, mainly in Europe and Siberia. Note that over the northern latitudes the number of observations is reduced mainly due to the presence of snow. For the FAPAR (Figure 4-b), large areas are observed with significant systematic differences. The grey area representing mean annual differences of 0.05 FAPAR units constitute only $47.2 \%$ of the total vegetated pixels. Both FAPAR products are spatially consistent for Broadleaf Forest; however, MODC5 FAPAR displays a positive bias over sparsely vegetated areas (mostly classified as Shrubs by MODIS). Conversely, GEOV1 FAPAR provides again higher values over regions classified as Broadleaf Crop (e.g., see regions over USA or Ukraine). The largest mean difference goes up to +0.2 over a large region of Siberia, dominated by Needle-leaf forest and Shrubs according to the MODIS land cover. For both LAI and FAPAR products, large systematic discrepancies are also observed in central Africa, in the northern area of the equatorial dense forest of the Congo River basin, covering large areas of Central African Republic and South Sudan.These differences will be qualitative analyzed in the next section over selected pixels. 


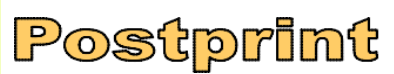

Version définitive du manuscrit publiée dans / Final version of the manuscript published in :

Remote Sensing of Environment (2013), Vol. 137, p. 310-329, DOI: 10.1016/j.rse.2013.02.030

Journal homepage: www.elsevier.com/locate/rse
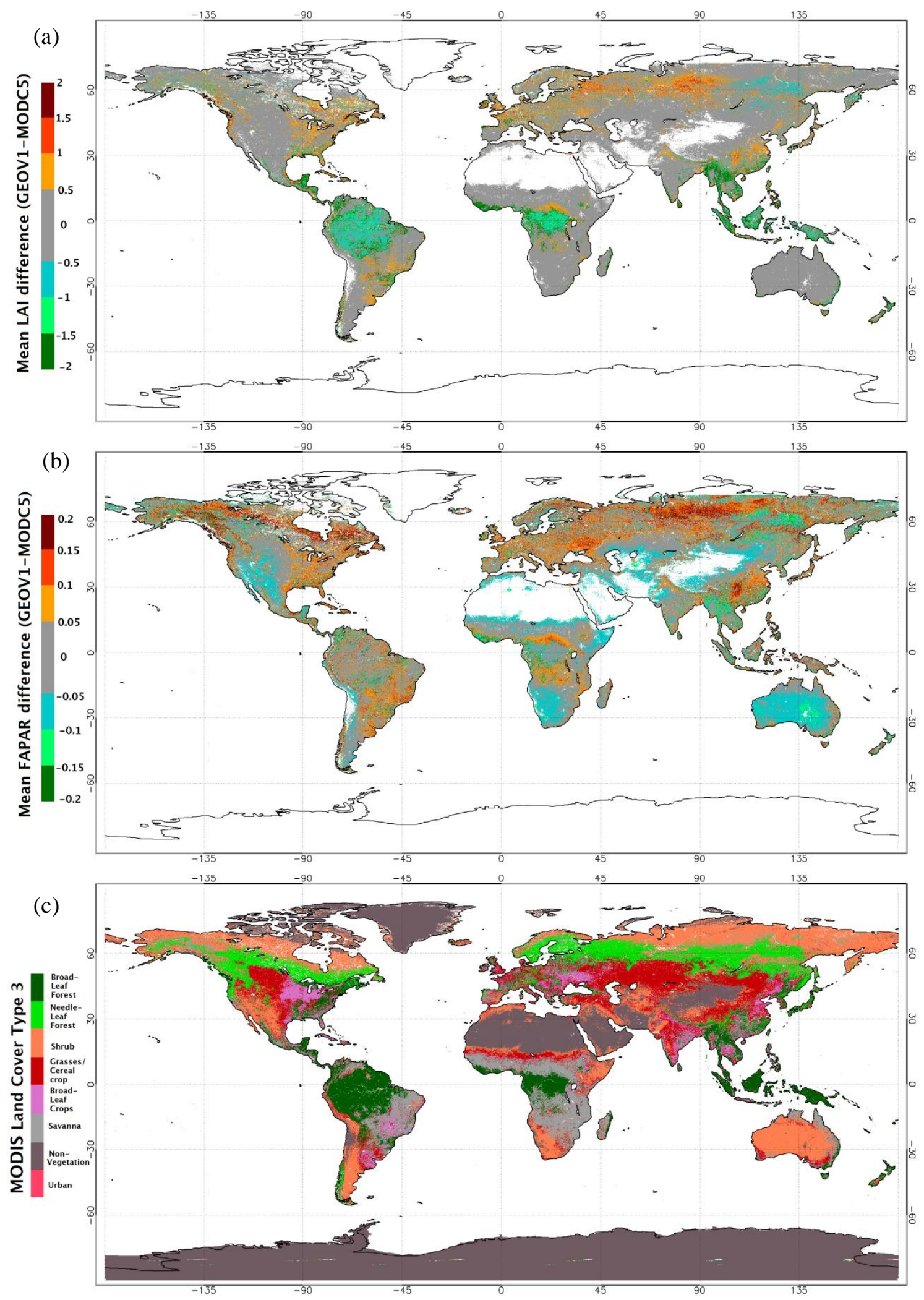

Figure 4: Panel (a) shows the mean annual LAI difference (GEOV1-MODC5) for the period 20032005. The grey areas represent changes within \pm 0.5 LAI units, whereas white color denotes water, ice or bare areas. Panel (b) shows the mean annual FAPAR difference (GEOV1-MODC5) for the same period. Here, grey areas represent changes within \pm 0.05 FAPAR units, whereas white color is used for water, ice and bare areas. Panel (c) shows the MODIS 8-biomes land cover. 
TEMPORAL CONSISTENCY

\subsubsection{Seasonality}

For each ofthe main biome classes, two sites were selected to illustrate the typical seasonality observed over the 2003-2005 period. BELMANIP-2 (B-2) sites located over areas displayinglarger discrepancies between MODIS and GEOV1 were selected to better analyze the observed annual mean difference. Moreover, several 'direct' sites where ground measurements are available were selected, but no comments will be provided on the agreement with the considered products since these measurements correspond only to a single date. More significant comparison with ground measurements will be presented later, based on the ensemble of available ground measurements.

Over the Broadleaf Evergreen Forest site (B-2\#33) in the Amazon forest (Brazil) (Figure 5-a), GEOV1 and CYCV31 products present smooth temporal variations, with GEOV1 LAI values closer to MODIS. MODC5 LAI presents very noisy profiles, which could be partly due to the high sensitivity of MODC5 retrievals to surface reflectance uncertainties for large LAI values (Shabanov et al., 2005). GLOV2 presents very unrealistic LAI seasonality not expected for this type of forest site, as observed in other evergreen forest sites in Amazon and Congo basin. GEOV1 provides high FAPAR values similar to that of MODIS.MODC5 FAPAR temporal profile is very noisysimilarly to MODC5 LAI product. The JRC-FAPAR product providesalso noisy profiles but with much lower valueswhich are unexpected for this very dense canopy. The GEOV1 FCOVER shows high values as expected, whereas CYCV31 displays the systematic underestimation that was already noticed by Camacho et al., (2006).

Over the Camerons dry Broadleaf Evergreen Forest site in Western Australia, GEOV1, CYCV31 LAI and FCOVER as well as MODC5 LAI present almost no seasonality as expected for this dry forest (Figure 5-b). Conversely, GLOV2 LAI displays unexpected seasonal variations with values up to 5 during 2003, and large inter-annual variations. Similar unrealistic results were found for GLOV2 over several sites (Garrigues et al., 2008a). GEOV1 and CYCV31 FAPAR products show the same seasonal variations over the period, with higher values around June. This mainly corresponds to the increase of the optical path between January (low sun zenith angles $\theta \mathrm{s}=28^{\circ}$ ) and June (high sun zenith angles: $\theta \mathrm{s}=62^{\circ}$ ). MODC5 and JRCFAPAR products show only limited seasonal variations, although these black-sky FAPAR products should be sensitive to the seasonal variation of the sun position. GEOV1 or CYCV31 and GLOV2 show the smoothest profiles. 
Version définitive du manuscrit publiée dans / Final version of the manuscript published in :

Remote Sensing of Environment (2013), Vol. 137, p. 310-329, DOI: 10.1016/j.rse.2013.02.030

Journal homepage: www.elsevier.com/locate/rse

(a)
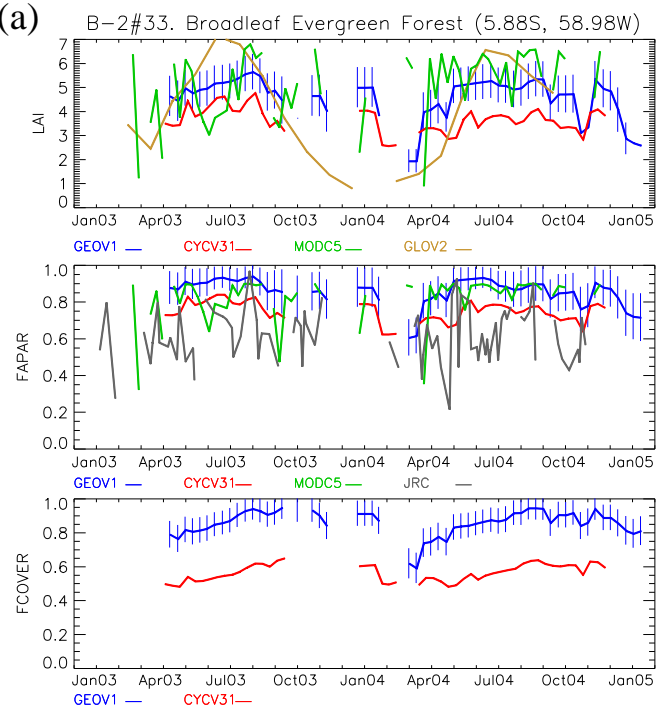

(b)
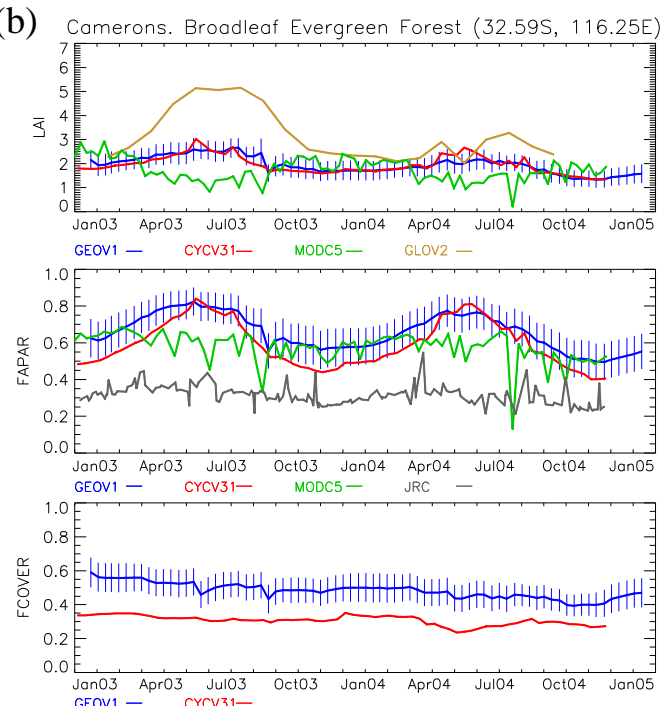

Figure 5: Temporal profile of GEOV1, CYCV31, MODC5, GLOV2 LAI and JRC FAPAR LAI (top), FAPAR (center) and FCOVER (bottom) over 2 sites of Broadleaf Evergreen Forest. Vertical bars for GEOV1 products correspond to the uncertainties $( \pm \sigma)$.

Over the Järvselja (Figure 6-a)and B-2\#406 (Figure 6-b) Needle-leaf boreal forest sitesin Estonia and Siberia (Russia) respectively, GEOV1, MODC5 and GLOV2 LAI products display similar magnitude and dynamic range conversely to CYCV31 that present lower values. GLOV2 LAI shows unexpected variations from year to year in Järvselja. MODC5 products display unrealistically strong temporal variations in agreement with Kobayashi et al., (2010). The strong fall in the MODC5 LAI/FAPAR retrievals around the peak values may partly explain the mean annual LAI/FAPAR differences between GEOV1 and MODC5 products observed over a large region of Siberia (Figure 4). FAPAR GEOV1 is close to MODC5 and systematically higher than CYCV31 as expected. The error bars for FAPAR cover typically the range of variations between CYCV31 and MODC5 estimates while large and systematic differences are observed with the JRC-FAPAR.GEOV1 FCOVER shows higher values consistent with that of the LAI product.

(a)

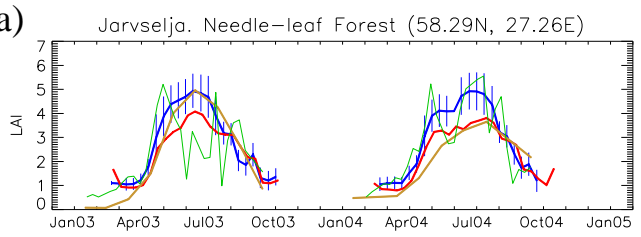

GEOV1 -
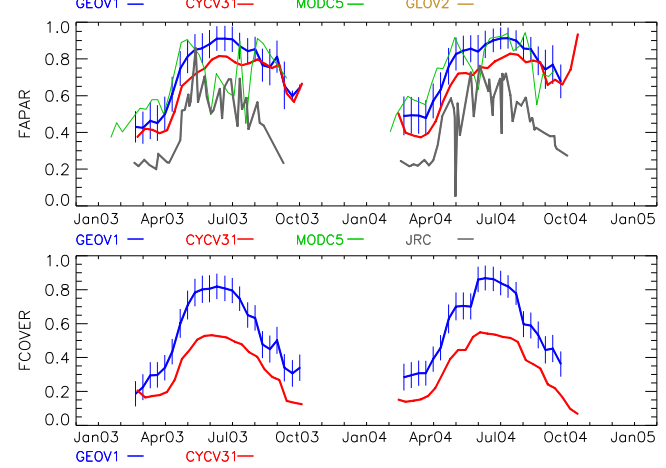

(b)

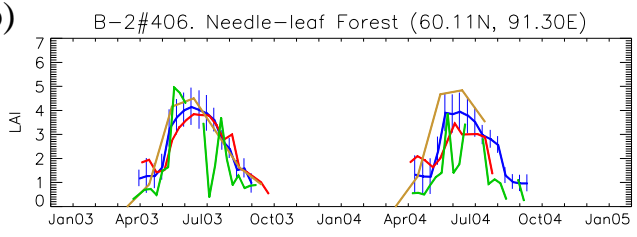

$$
\text { GEOV1 - }
$$
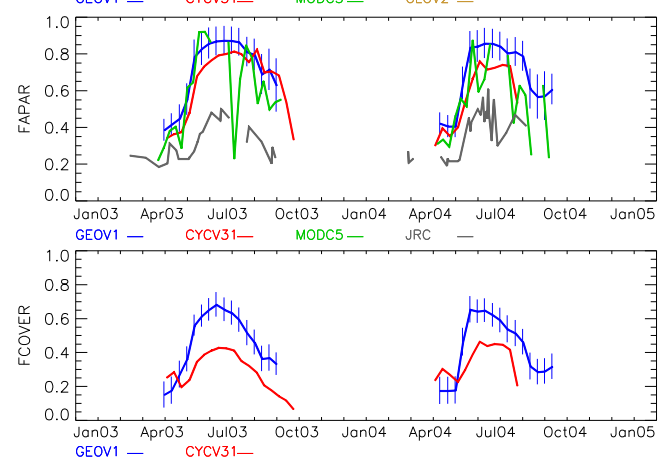
Version définitive du manuscrit publiée dans / Final version of the manuscript published in :

Remote Sensing of Environment (2013), Vol. 137, p. 310-329, DOI: 10.1016/j.rse.2013.02.030

Journal homepage: www.elsevier.com/locate/rse

Figure 6: idem Figure 5, but for a Needle-leaf forest (left) and a Mediterranean forest (right).

Over Broadleaf Deciduous Forest (Harvard in USA and BELMANIP-2\#159 in Central Africa Republic) sites, all the products show similar seasonal and inter-annual variations. GEOV1 and MODC5 LAI/FAPAR products have almost the same magnitude in Harvard (Figure 7-a), while MODC5 appears more unstable. GLOV2 and CYCV31 LAI products display lower values. The JRC-FAPAR presents the lowest values and is also quite unstable during the summer. The FCOVER GEOV1 product reaches the maximum values during summer time in agreement with the high LAI retrievals. Similar results are observed in B-2\#159 (Figure 7-b), where GEOV1 provides much higher LAI values than MODIS during the maximum of the seasonal cycle, which explains the large differences observed in northern Congo River basin (Figure 4). Furthermore, MODIS LAI displays unrealistic variations during the maximum development which contribute to the observed discrepancies.

(a)
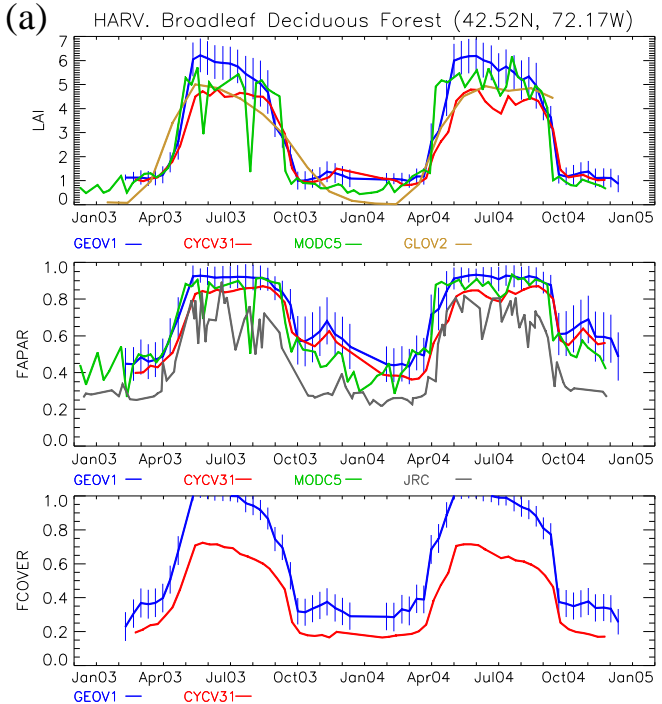

(b)
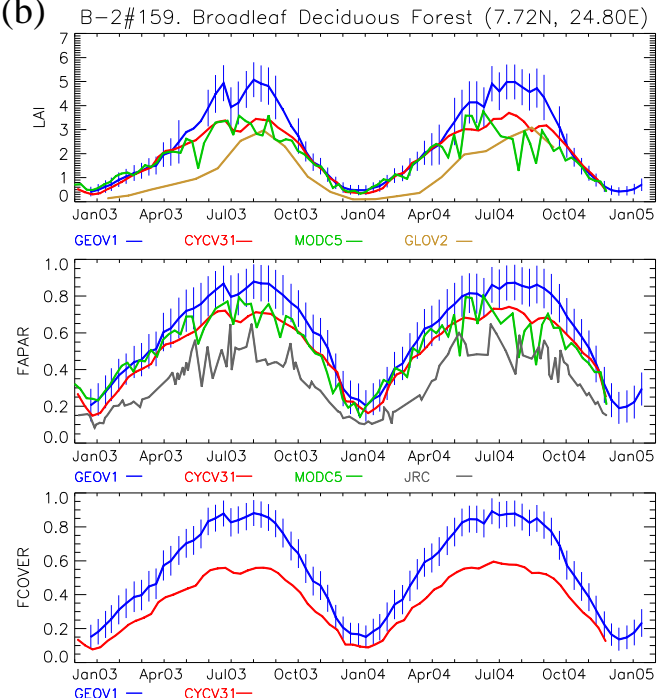

Figure 7: idem Figure 5, but for twoBroadleafDeciduous Forest sites.

Over cultivated sites (Fundulea, mainly composed of large winter and summer crops in Romania and BELMANIP-2\#91 in Iowa, USA). In Fundulea (Figure 8-a) all the LAI products show consistent seasonality. The main discrepancies appear for the FAPAR products: GEOV1 and CYCV31 present a secondary FAPAR peak in winter time corresponding to significant wheat crop development observed under high sun zenith angles. MODC5 presents lower valueswhile no observations are available for JRC-FAPAR during winter, and systematically lower values in summer. Over the B-2\#91 site (Figure 8-b), classified as Broadleaf Crops by MODIS, all the products present similar seasonality, but MODIS LAI present lower magnitude. GEOV1 LAI provides higher values during the peak, which explain the observed systematic differences over the large region of northeast USA classified as Broadleaf Crops (Figure 4).FCOVER GEOV1 and CYCV31 shows consistent time series with those of LAI and FAPAR, with CYCV31 systematically lower than GEOV1 as expected. 
Version définitive du manuscrit publiée dans / Final version of the manuscript published in :

Remote Sensing of Environment (2013), Vol. 137, p. 310-329, DOI: 10.1016/j.rse.2013.02.030

Journal homepage: www.elsevier.com/locate/rse

(a)
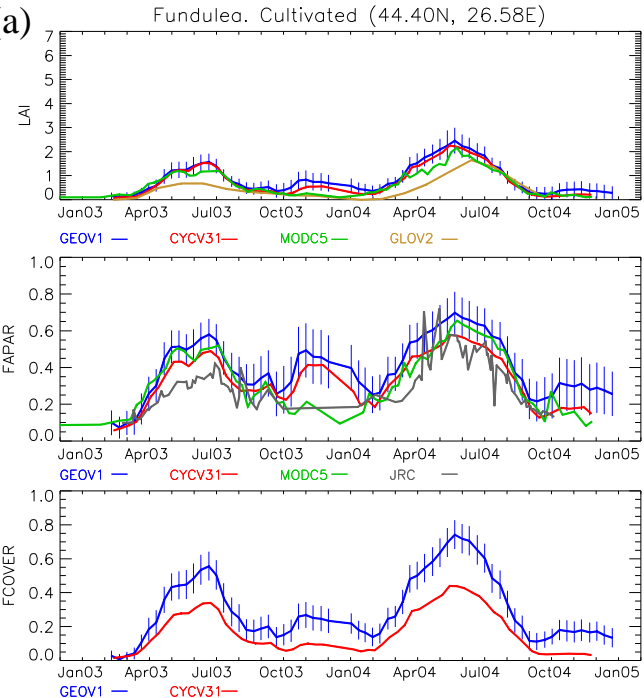

(b)
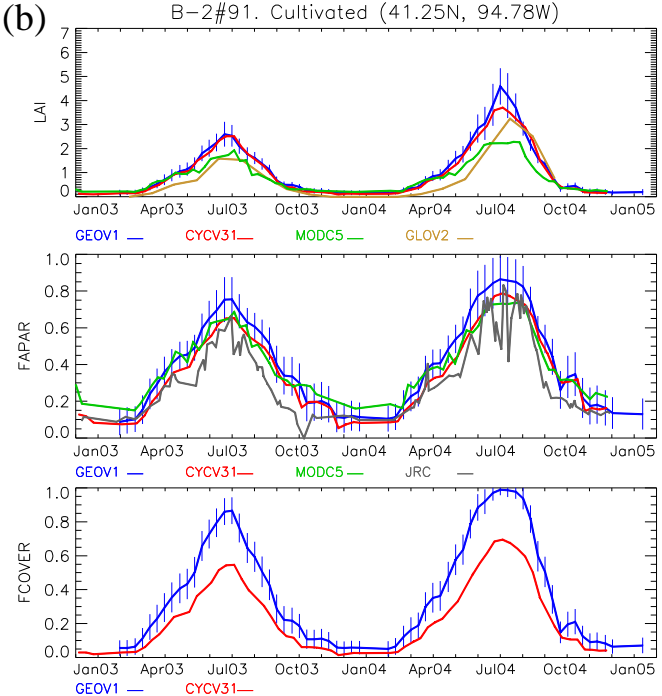

Figure 8: idem Figure 5, but for two Cultivatedsites.

Over Herbaceous (Wankama in Niger and Hambori in Mali) sites (Figure 9), the several LAI, FAPAR and FCOVER products reproduce well the rapid increase of the vegetation during the rain season with the exception of GLOV2 that displays very low values along the year. GEOV1 LAI and FAPAR products are close to the CYCV31 retrievals over these sites as expected. Conversely, MODC5 FAPAR displays an over-estimation around 0.1 FAPAR values during the dry season, and thus a lower dynamic range of the vegetation is shown. JRC-FAPAR shows the lowest values.

(a)
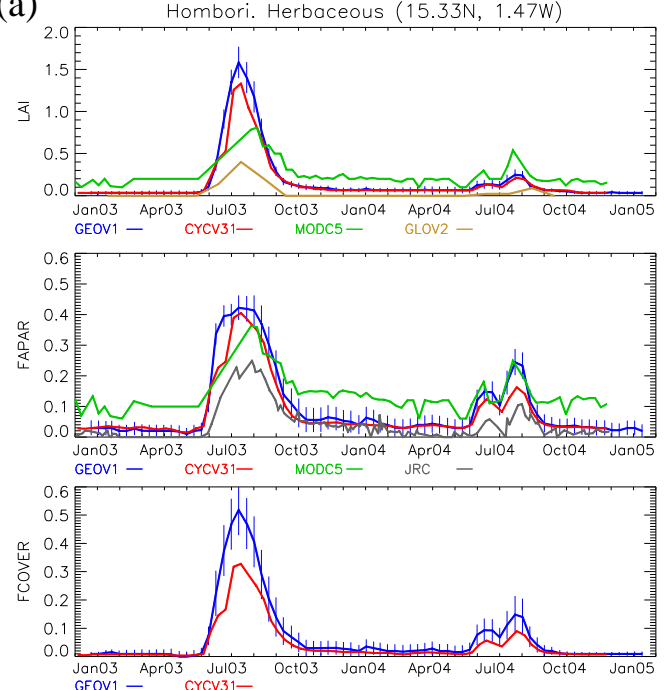

(b)
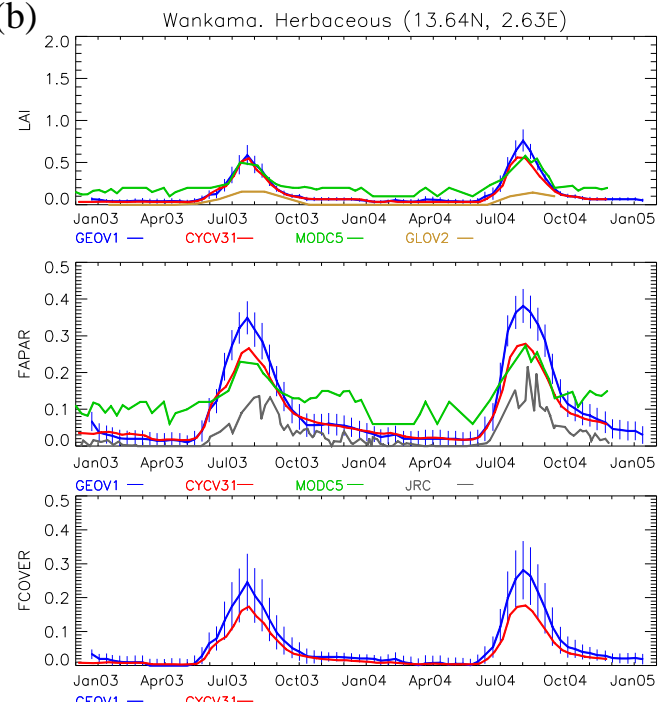

Figure 9: idem Figure 5, but for two Herbaceous sites.

Over Shrublands and Sparse (Sevilleta in USA and BELMANIP-2\#124 in Iowa, USA) sites (Figure 10), all the products show very low values as expected, with little seasonality. However, MODC5 FAPAR shows again systematically higher values than the other FAPAR products, which introduces systematic bias over sparsely vegetated areas, as observed at global scale (Figure 4). 
Version définitive du manuscrit publiée dans / Final version of the manuscript published in :

Remote Sensing of Environment (2013), Vol. 137, p. 310-329, DOI: 10.1016/j.rse.2013.02.030

Journal homepage: www.elsevier.com/locate/rse

(a)
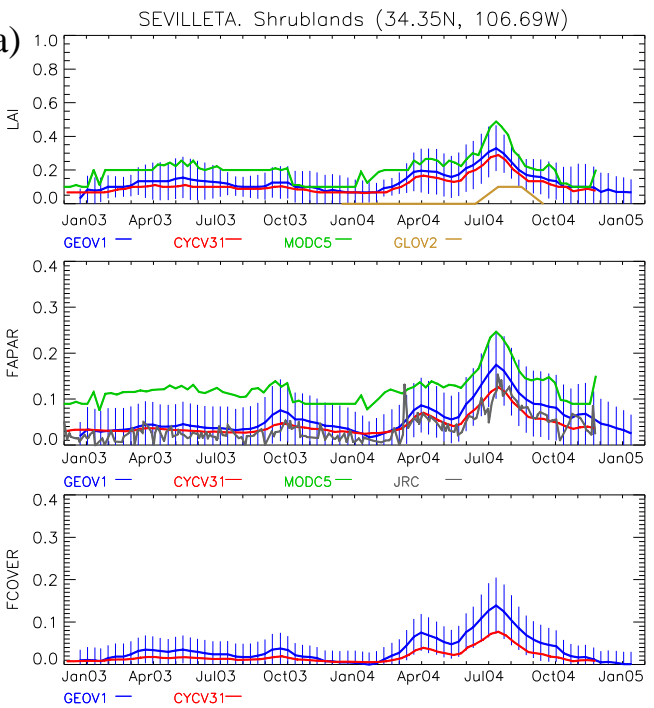

(b)
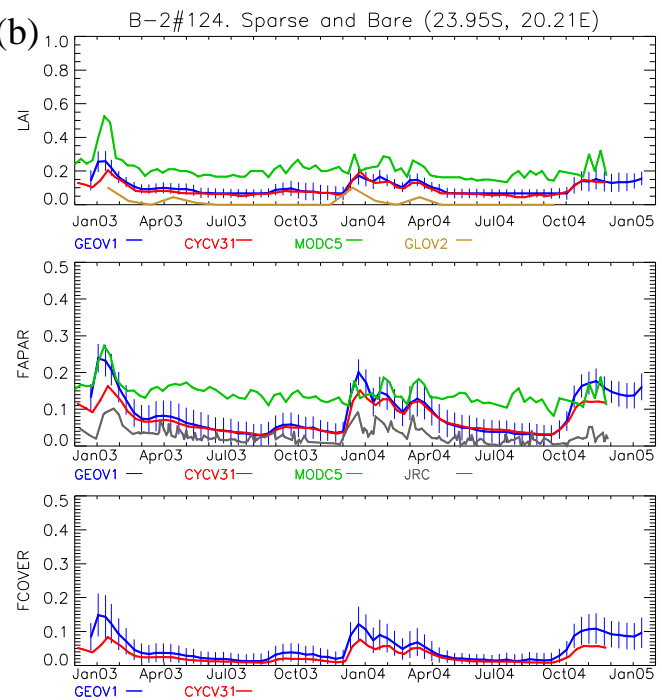

Figure 10: idem Figure 5, but for two Shrublands sites.

These several examples show some generic qualitative traits among the several products. GEOV1 LAI and FAPAR products show generally realistic time courses, both in terms of seasonality and range. Further, along with CYCV31 and GLOV2, the temporal profiles are smooth as expected, conversely to MODC5 and in a lesser way JRC-FAPAR that are relatively shaky which is expected for JRC since no compositing algorithm is applied to this daily product. GLOV2 LAI products seem to describe unrealistic seasonality mainly over broadleaf evergreen forest sites. GEOV1 is generally in between CYCV31 and MODC5, the differences between these products being in good agreement with the GEOV1 error bars. JRC-FAPAR is systematically lower than the other FAPAR products, except for the lowest FAPAR values where MODC5 seems to have difficulties to be lower than 0.1. Some inconsistencies in seasonality is observed between the several FAPAR products during winter (north hemisphere) or summer (south hemisphere) presumably due to the effect of the sun position at the time of satellite overpass. GEOV1 FCOVER is systematically higher than its precursor CYCV31 product as expected. These qualitative generic traits shortly described above will be better quantified in the next steps.

\subsubsection{Temporal smoothness}

The distributions of $\delta$ LAI, $\delta$ FAPAR and $\delta$ FCOVER were analyzed over the BELMANIP2 set of sites (Figure 11). Note however that $\delta$ FCOVER will not be described here for the sake of brevity since CYCV31 and GEOV1 present the same features as those of LAI and FAPAR products. Results on LAI show that CYCV31 and GEOV1 have thehighest frequencies for the lowest $\delta \mathrm{LAI}$ values, which demonstrates that temporal smoothness is the best for these products based on CYCLOPES preprocessing chain. Conversely, both MODC5 and GLOV2 LAI products present distributions shifted towards the higher $\delta$ LAI values. However, GLOV2 is a monthly product for which larger differences between interpolated and retrieved values are expected. The same features are observed for GEOV1, CYCV31 and MODC5 FAPAR products which were expected since LAI and FAPAR products share the same temporal resolution and preprocessing steps within each product family. Finally, the JRC-FAPAR product shows more shaky temporal profiles, mainly because of its daily temporal frequency. These quantitative 
Version définitive du manuscrit publiée dans / Final version of the manuscript published in :

Remote Sensing of Environment (2013), Vol. 137, p. 310-329, DOI: 10.1016/j.rse.2013.02.030

Journal homepage: www.elsevier.com/locate/rse

results confirm the previous qualitative observations derived from the temporal profiles over the selected sample of sites.

(a)

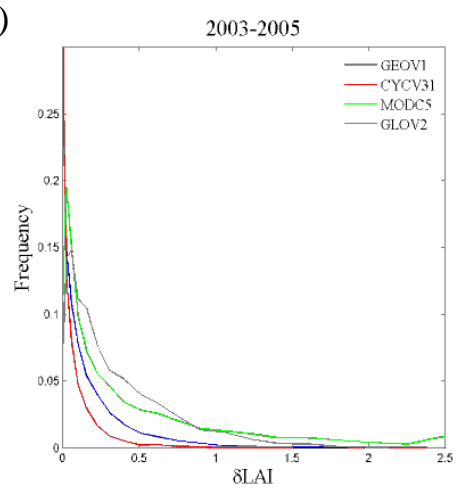

(b)

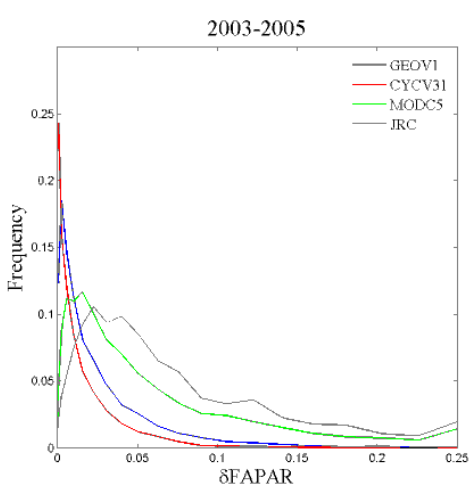

Figure 11: Temporal smoothness for (a) LAIand (b) FAPARproducts.

\subsection{BULK STATISTICAL ANALYSIS}

\subsubsection{Distribution of products as a function of the biome type}

The distributions of LAI are relatively consistent across the four products investigated for all the biome types except Broadleaf Evergreen Forest (Figure 12). Note however that some slight discrepancies are observed for BDF and NLF for the very low LAI values where GLOV2 shows the lowest frequency of low (but non zero) values. For the higher LAI values over BDF and NLF, CYCV31 shows the lowest frequencies in relation to the identified early saturation. Over $\mathrm{EBF}$, differences between the distributions of LAI values are exacerbated. Modes are reached for very different LAI values for CYCV31 (LAI=3.5), GLOV2 (LAI=4.0) showing a more even distribution, GEOV1 (LAI=5.0) and MODC5 (LAI=6.0). GEOV1 shows a distribution closer to that of MODC5 as expected for these supposedly high LAI values, with values larger than 6.5 reached in few occasions. 
Version définitive du manuscrit publiée dans / Final version of the manuscript published in :

Remote Sensing of Environment (2013), Vol. 137, p. 310-329, DOI: 10.1016/j.rse.2013.02.030

Journal homepage: www.elsevier.com/locate/rse

(a)

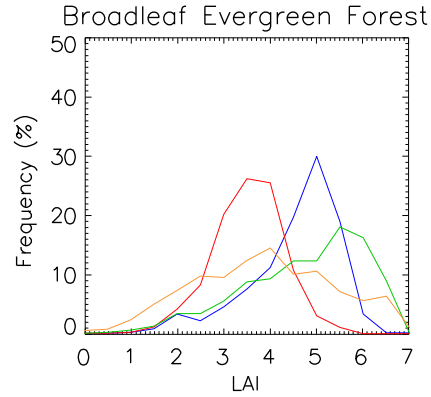

(d)

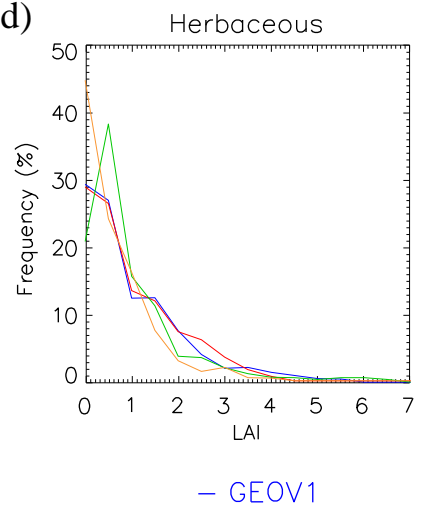

(b)

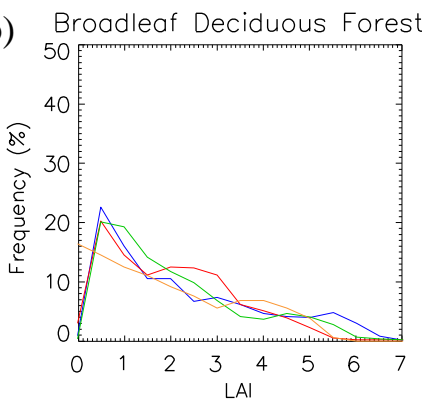

(e)

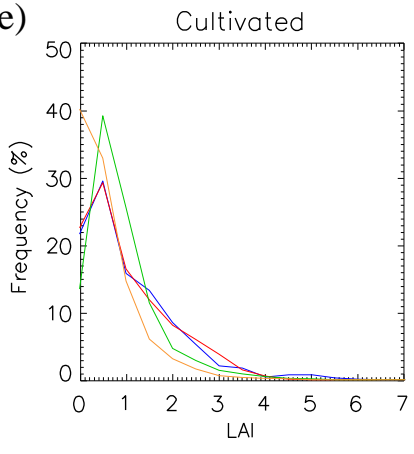

- CYCV31

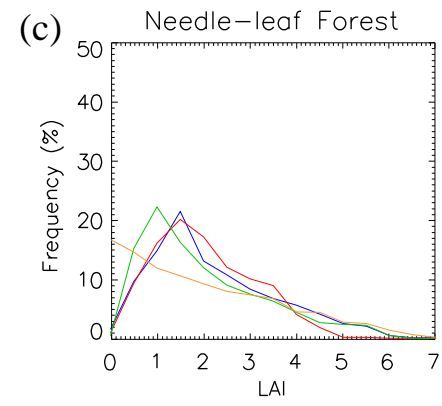

(f)

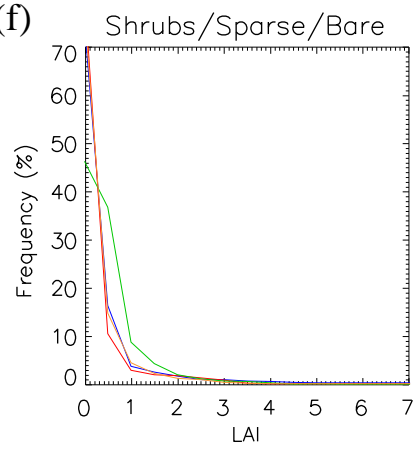

- GLOV2

Figure 12. Distribution of LAI values of each product for the BELMANIP-2 sites during the 20032005 period for each biome type.

Distributions of FAPAR values (Figure 13) for Shrubs, Sparse and Bare areas, Cultivated and Herbaceousare similar between GEOV1, CYCV31 and JRC-FAPAR with JRC-FAPAR presenting lower values in Cultivated and Herbaceous. Conversely, MODC5 shows clearly the overestimation of the very low FAPAR values. Over Forest biomes, much larger differences are observed particularly regarding JRC-FAPAR that shows very limited frequencies for the higher FAPAR values, in agreement with the underestimation reported previously on the individual temporal profiles. GEOV1 shows generally the highest FAPAR values. Note that the differences between products, particularly with JRC-FAPAR are very large and far beyond what is expected from the user point of view. 
Version définitive du manuscrit publiée dans / Final version of the manuscript published in :

Remote Sensing of Environment (2013), Vol. 137, p. 310-329, DOI: 10.1016/j.rse.2013.02.030

Journal homepage: www.elsevier.com/locate/rse

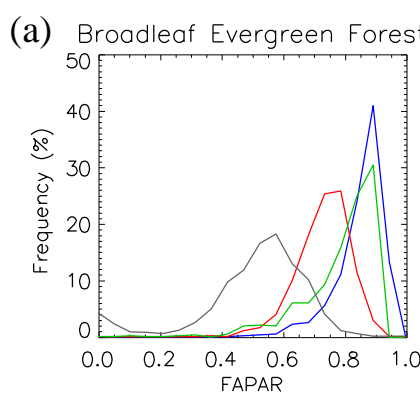

(d)

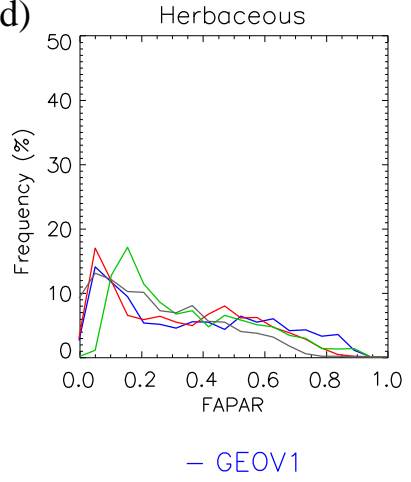

(b)

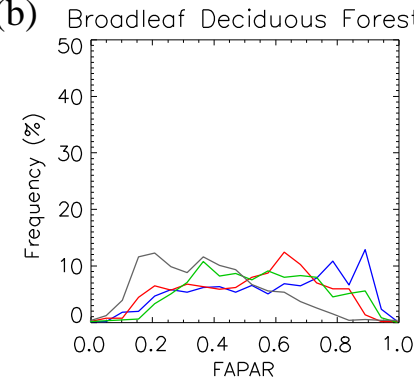

(e)

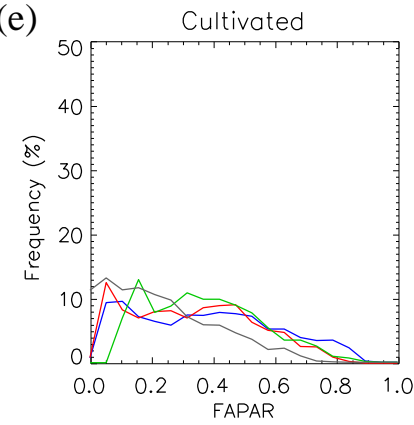

$-\mathrm{CYCV} 31$ (c)

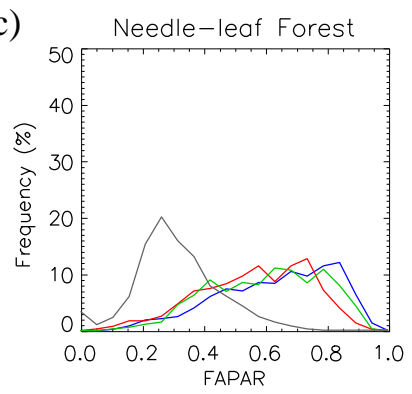

(f)

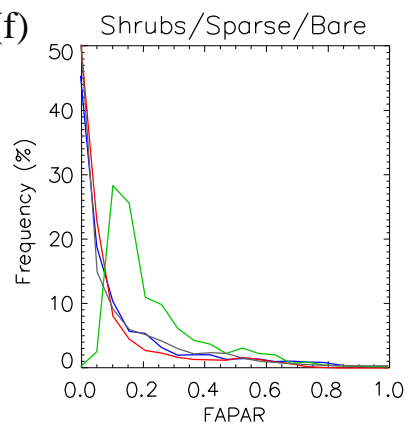

$-J R C$

Figure 13. Distribution of FAPAR values of each product for the BELMANIP-2 sites during the 2003-2005 period for each biome type.

Differences in the distribution of FCOVER values (Figure 14) between GEOV1 and CYCLOPES show similar features as for the FAPAR distributions: an increase of the frequencies for the larger FCOVER values, mostly due to the scaling factor applied to CYCV31 to get GEOV1 (Baret et al., 2012). A significant fraction of values is now observed with FCOVER values close to 1.0 over the forest sites as expected, particularly the deciduous and evergreen broadleaf forests.

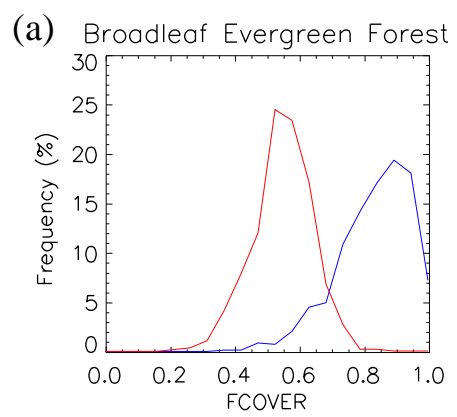

(b)

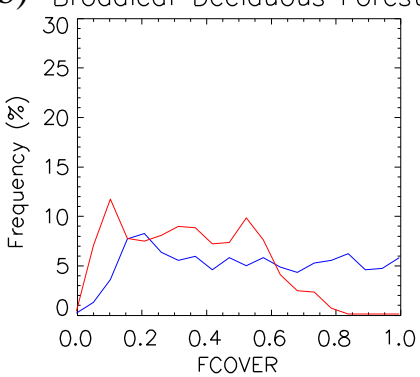

(e)

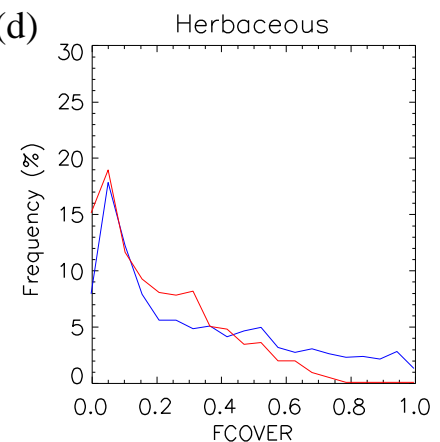

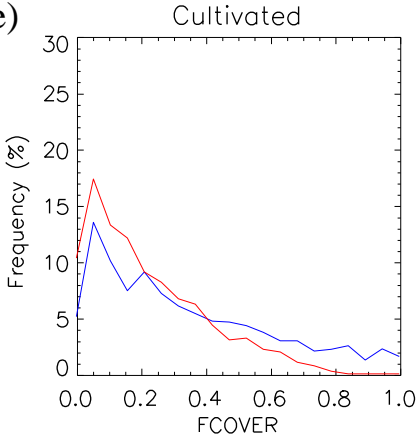

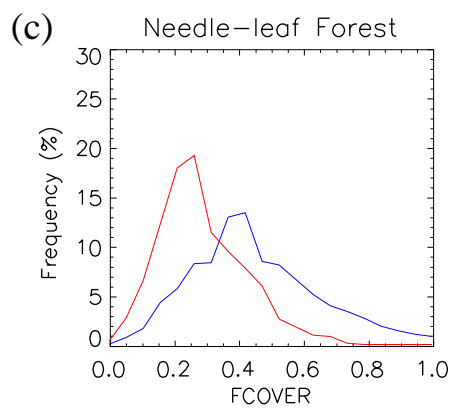

(c)

(f)

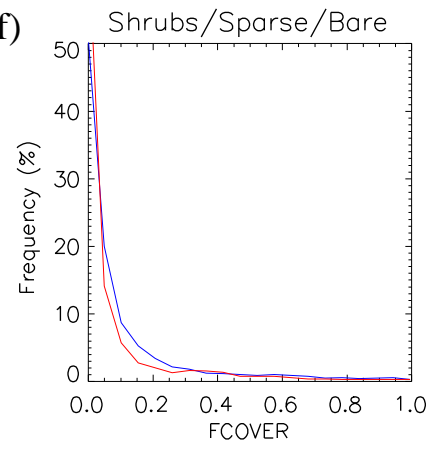


Version définitive du manuscrit publiée dans / Final version of the manuscript published in :

Remote Sensing of Environment (2013), Vol. 137, p. 310-329, DOI: 10.1016/j.rse.2013.02.030

Journal homepage: www.elsevier.com/locate/rse

Figure 14.Distribution of FCOVER values of each product for the BELMANIP-2 sites during the 2003-2005 period for each biome type.

\subsubsection{Consistency between GEOV1 and the other products}

GEOV1 LAI shows a high correlation with the other LAI products, which goes up toR ${ }^{2}=0.9$ with CYCV31 (Figure 15-a). This is not surprising since both GEOV1 and CYCV31 products are based on similar preprocessed VGT observations (only the weights in the temporal compositing change) and GEOV1 neural network is trained with a large contribution of CYCV31 products. However, the scatter-plots show that the higher LAI values of GEOV1 depart from those of CYCV31 when MODC5 starts to contribute significantly to the training of GEOV1. This creates a positive bias between GEOV1 and CYCV31. Conversely, no significant bias is observed between GEOV1 and MODC5 (only for very low LAI values MODIS displays higher values) although the scattering ( $\mathrm{S}=0.66)$ is relatively large, mainlycoming from the short time scale instability noticed earlier for MODC5 (Figure 13-b). The comparison between GEOV1 and GLOV2 provides lower agreement (RMSE=0.85) with both a significant scattering $(\mathrm{S}=0.76)$ and a positive bias $(\mathrm{B}=0.36)$ mainly coming from the lower LAI values (Figure $13-\mathrm{c}$ ).

(a)

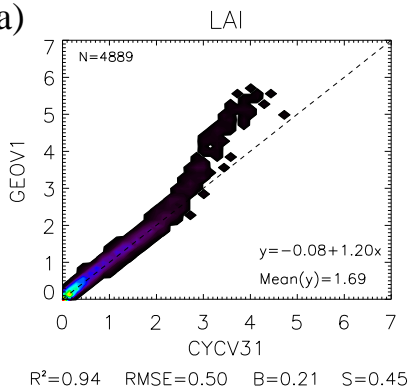

(d)

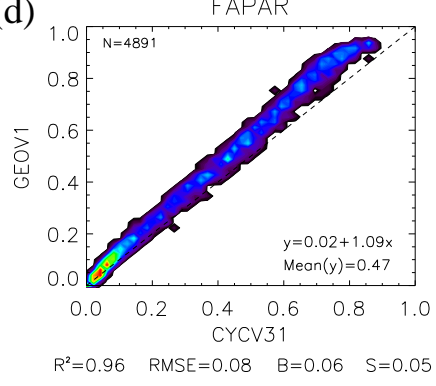

(b)

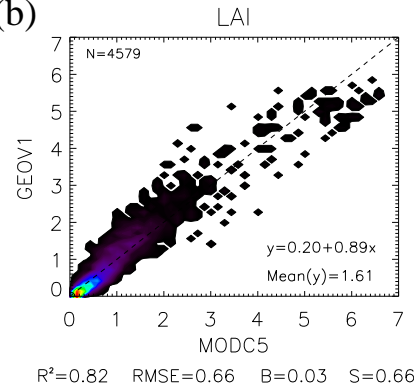

(e)

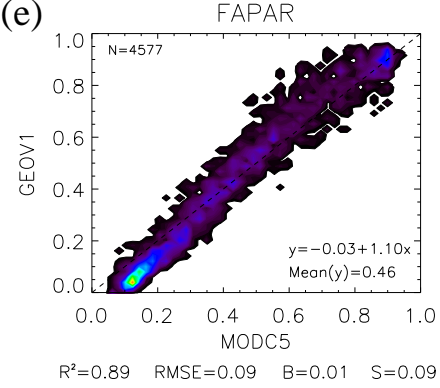

(c)

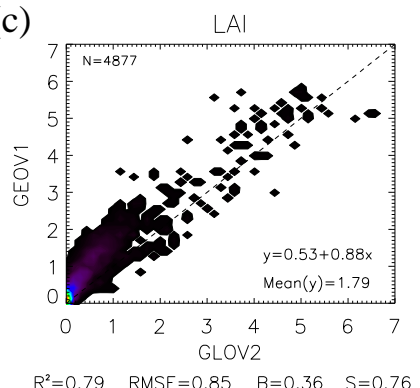

(f)

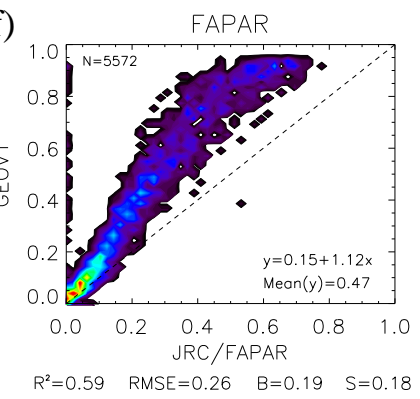

Figure 15: Product versus product scatter-plots over all BELMANIP-2 sites using the LAI (top), FAPAR (bottom) values from the 24 months of the 2003-2005 period. The terms B and $S$ represent the mean and the standard deviation of the difference between the GEOV1 retrievals displayed in the $y$ axis and those shown in the $x$ axis.

For FAPAR, the best consistencyis found between GEOV1 and CYCV31 FAPAR products with a correlation of $\mathrm{R}^{2}=0.95$ (Figure 15-d). This is obviously explained by the very important contribution of CYCV31 in the training of GEOV1 FAPAR since MODC5 contribution is only significant for FAPAR values higher than 0.8. GEOV1 provides higher values than those of the CYCV31 products because of the scaling applied in the learning process (Baret et al., 2012). The comparison between GEOV1 and MODC5 FAPAR shows alsoa good correlation, with no mean bias although MODC5 FAPAR displays a positive bias for low values as observed in other studies (Figure 15-e). A good overall consistency between both products is found, with overall discrepancies lower than 0.1 mainly coming from the MODC5 short term instability. The comparison of GEOV1 with JRC-FAPAR is relatively poor with significant scattering and 
Version définitive du manuscrit publiée dans / Final version of the manuscript published in :

Remote Sensing of Environment (2013), Vol. 137, p. 310-329, DOI: 10.1016/j.rse.2013.02.030

Journal homepage: www.elsevier.com/locate/rse

systematic lower values for JRC-FAPAR as observed previously (Figure 15-f).Note also that a number of JRC-FAPAR $=0$ values correspond to a wide range of GEOV1 values.

Comparison between GEOV1 and CYCV31 FCOVER products shows a very strong linear correlation as expected since GEOV1 was derived from CYCV31 after applying a scaling factor (Baret et al. 2012). The results can be found at Camacho and Cernicharo (2010).

\subsubsection{Consistency between GEOV1 and MODC5 per biomes}

To further quantify the consistency between GEOV1 and MODC5 FAPAR/LAI products, all the best quality pixels for each main biomehave been considered. Box plots corresponding to the LAI bias (Figure 16-a) shows that median values are around zero for all biomes except BEF, with a $50 \%$ of the data encompassed between 0 and 0.5 LAI units, showing GEOV1 slightly higher values mainly in NLF and C. For BEF, GEOV1 presents typically lower values, with $50 \%$ of values between 0 and -1.2. Larger discrepancies can be explained due to the noisy retrievals obtained in MODIS for this biome. The LAI RMSE (Figure 16-b) is typically below 0.5 for $\mathrm{S}, \mathrm{H}$ and SBA, and between 0.5 and 1 for BDF and NLF, with higher values that could be partly explained by noisy MODIS retrievals. For the BEF, the median of the RMSE is about 1.5 , with values between second and third quartiles varying from 1.25 to 2 .
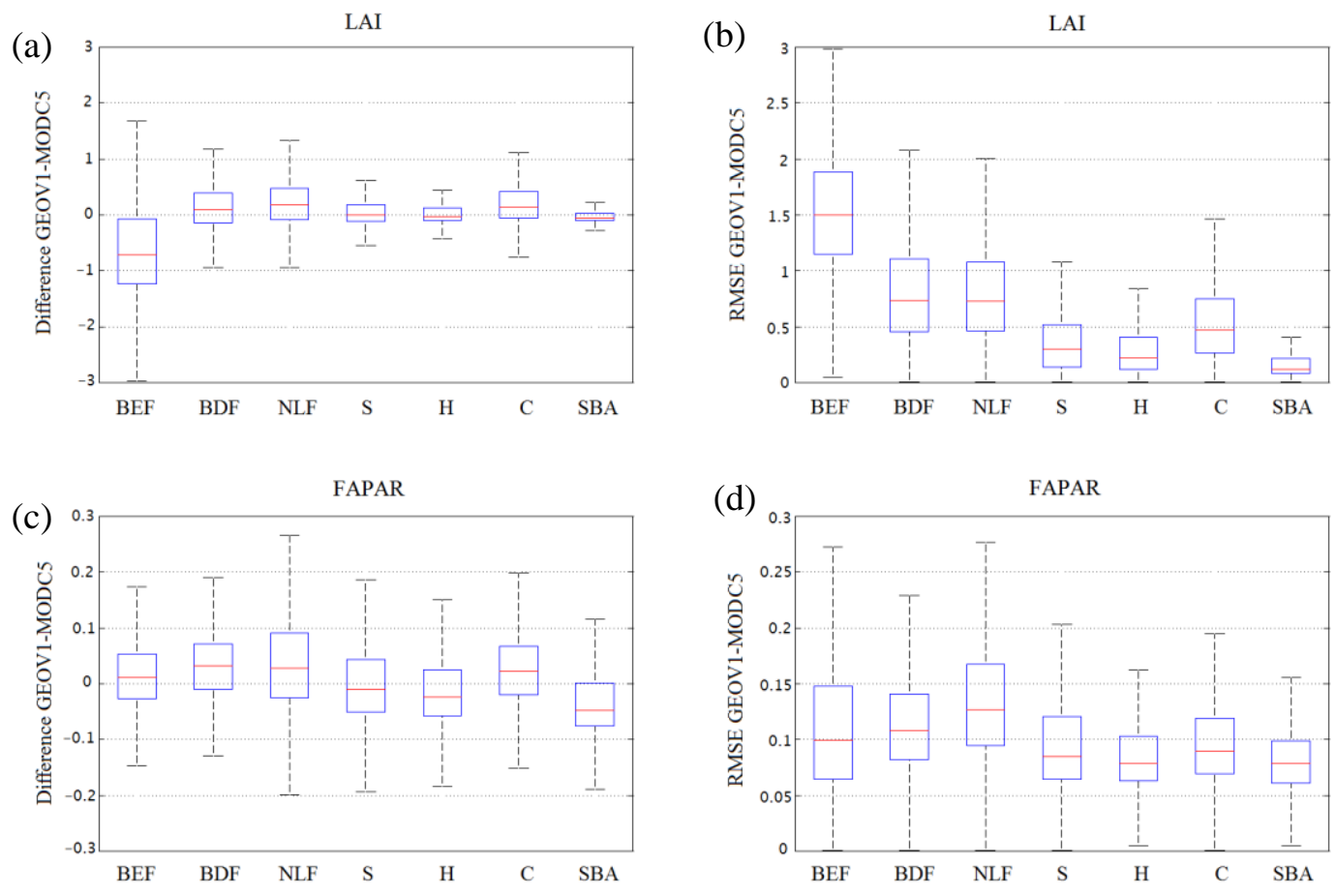

Figure 16: Box plots of the difference (left side) and RMSE (right side) between GEOV1 and MODC5 LAI (a, b) and FAPAR (c, d) products for all the best quality pixels of each biome.The box stretches from the 25 th percentile to the 75 th percentile. The median is show as a red line. The bars correspond to $\pm 2.7 \sigma(99.3 \%$ coverage $)$. Outliers are not displayed.

For the FAPAR product, the box plot of the difference between GEOV1 and MODC5 (Figure 16-c) shows that GEOV1 provides slightly higher values in BEF, BDF, NLF and Crops, whereas MODIS is slightly higher in Herbaceous and Sparse and Bare Areas. Note that the 
Version définitive du manuscrit publiée dans / Final version of the manuscript published in :

Remote Sensing of Environment (2013), Vol. 137, p. 310-329, DOI: 10.1016/j.rse.2013.02.030

Journal homepage: www.elsevier.com/locate/rse

largest differences are found for the NLF, a biome that covers large regions of Eurasia, and where strong unrealistic variations in the MODIS product have been observed. The box plot of RMSE (Figure 16-d) shows $50 \%$ of values between 0.06 and 0.12 for non-forest types, and slightly higher for forests, mainly for Needle-leaf Forest that shows $50 \%$ of values between 0.1 and 0.17 .

\subsection{DIRECT VALIDATION}

The best accuracy and precision areobserved for the GEOV1 LAI product (Figure 17). GEOV1 provides also very good agreement across the whole range of LAI values, with however only a slight underestimation for the highest values. CYCV31 presents important underestimation of the highest actual LAI values over Forests, as previously reported due to the early saturation of the LAI. Conversely, MODIS presents a good accuracy for the different biome types, but slightly degraded precision probably due to the reported instability over short time periods. GLOV2 displays important underestimation for Crops and Grass, and for the two dense forests.
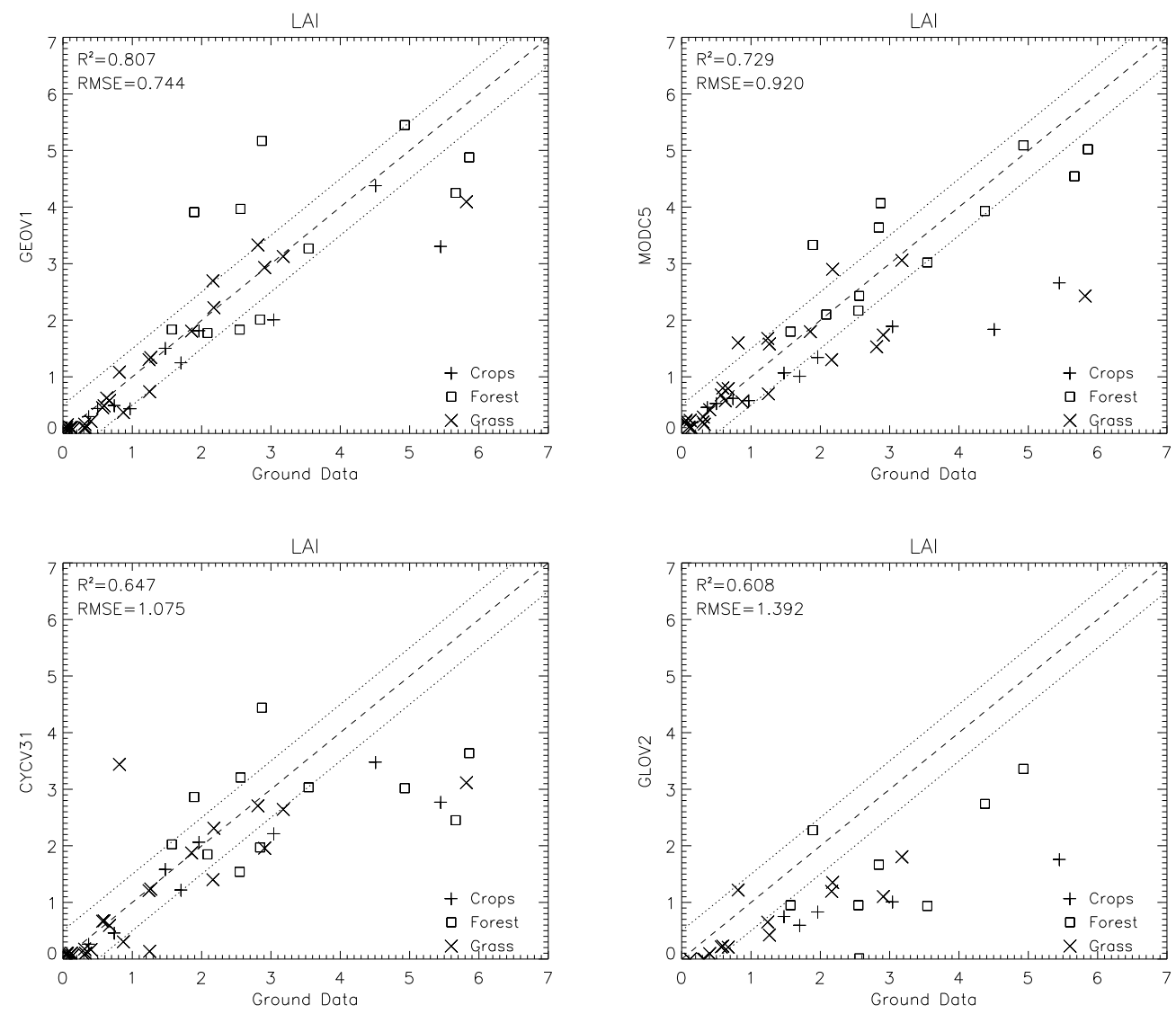

Figure 17: Direct validation results: comparison of each LAI product with the LAI ground-based maps. Forest refers to Broadleaf Evergreen, Broadleaf Deciduous and Needle-leaf Forests, Crops refers to Cultivated and Grass refers to Herbaceous, Shrublands, and Sparse and Bare Areas.

GEOV1 and MODC5 FAPAR (Figure 18) show the best performances as compared to the other products, regarding accuracy and precision. However, for MODIS an overestimation is 
Version définitive du manuscrit publiée dans / Final version of the manuscript published in :

Remote Sensing of Environment (2013), Vol. 137, p. 310-329, DOI: 10.1016/j.rse.2013.02.030

Journal homepage: www.elsevier.com/locate/rse

observable for two grassland sites with very low FAPAR ground values. No obvious outliers are observed over GEOV1 explaining the highest $R^{2}$ value achieved. CYCV31 FAPAR underestimates grassland and forest sites. JRC-FAPAR is characterized by a significant but consistent underestimation, confirming the previous observations. This is partly explained by the later overpass time of SEAWIFS as compared to VEGETATION or MODIS, but probably also by a lack of representativeness of the training data base used to calibrate the algorithm.
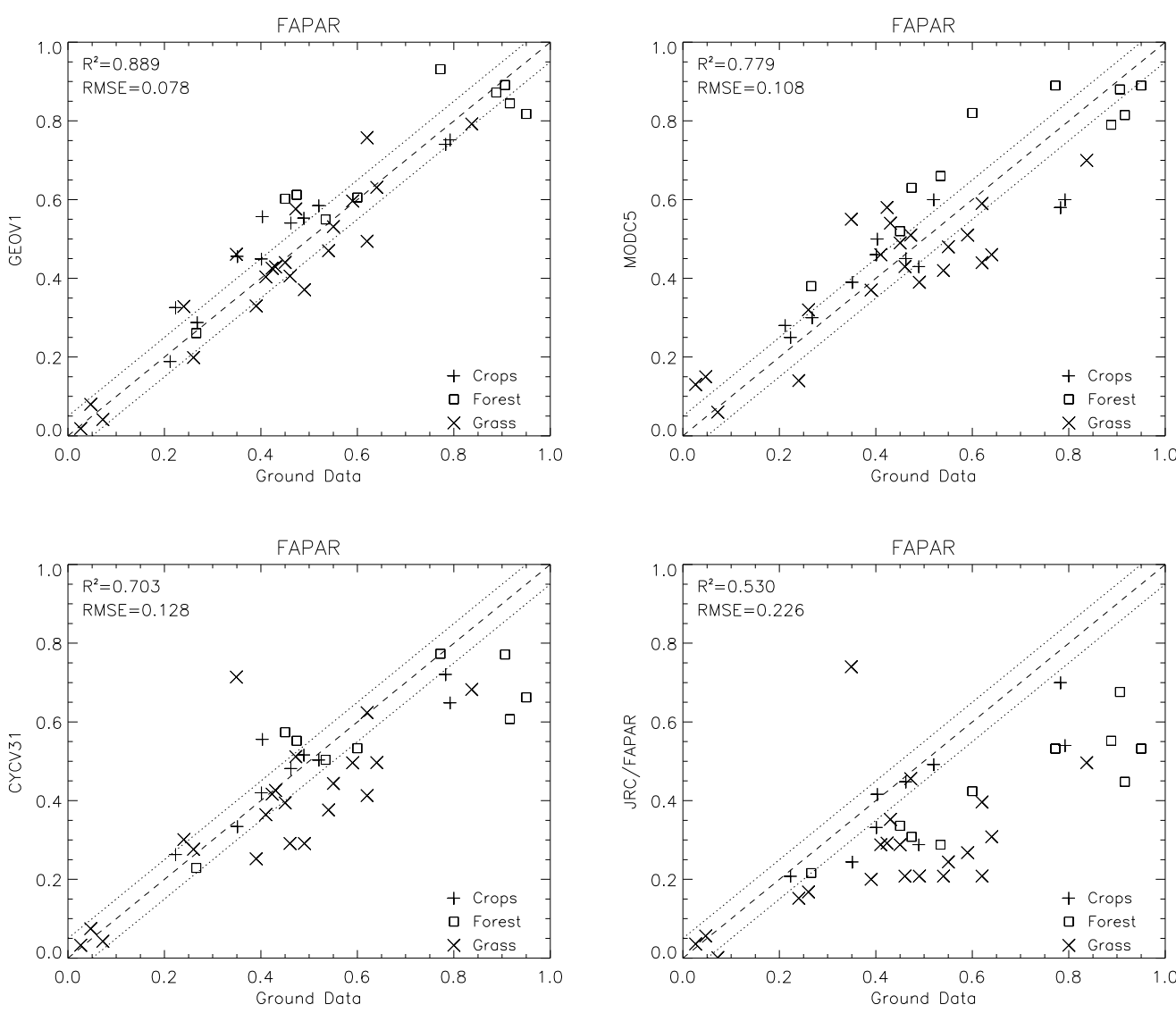

Figure 18: Same as Figure 17 but for FAPAR products.

The agreement of FCOVER GEOV1 with ground data is very good with almostno bias and good precision, although with some dispersion for intermediate values. These results outperform clearly those of CYCV31 that show an important and systematic underestimation of ground data as found previously over Europe (Verger, 2008) or over Africa (Camacho et al., 2006). 
Version définitive du manuscrit publiée dans / Final version of the manuscript published in :

Remote Sensing of Environment (2013), Vol. 137, p. 310-329, DOI: 10.1016/j.rse.2013.02.030

Journal homepage: www.elsevier.com/locate/rse
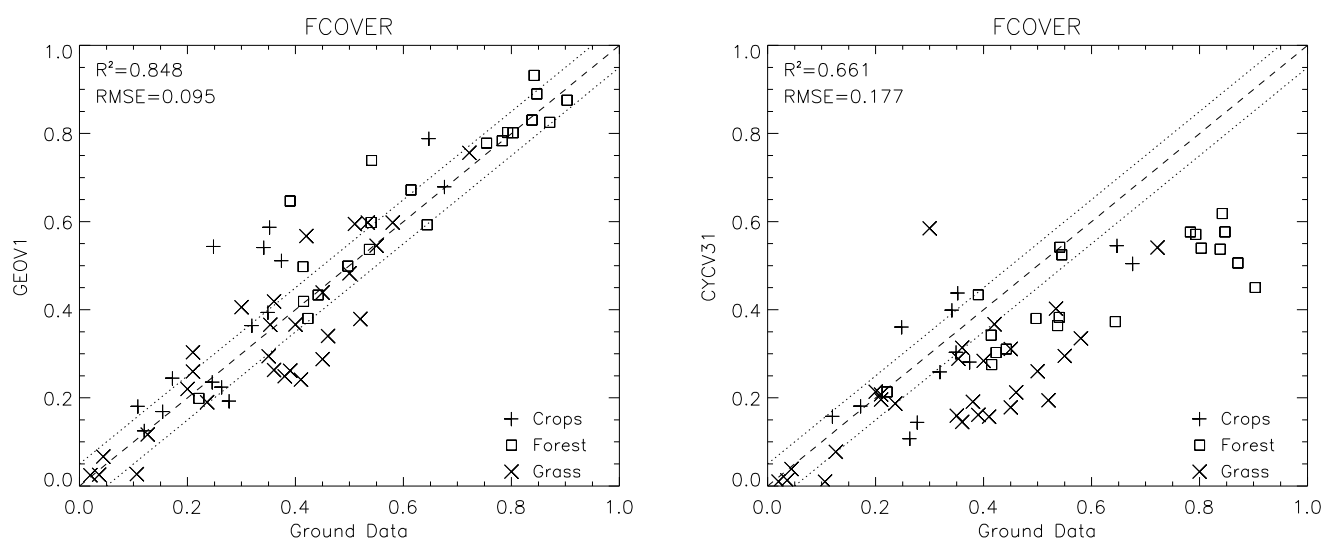

Figure 19: Same as Figure 17 but for FCOVER products.

Table 3 shows metrics of the direct validation. The RMSE of GEOV1 LAI is about 0.7, only slightly higher than the user requirement on LAI product accuracy (i.e., 0.5). GEOV1 LAI bias (S) and precision (B) improves that of its precursor products (CYCV31 and MODC5), as well as GLOV2 performances, providing the higher correlation and slope. For the FAPAR, the overall accuracy (RMSE) is around 0.08, similar to that of MODIS (RMSE $=0.11$ ), but with a better correlation, and slope. For FCOVER the RMSE of GEOV1 is around 0.1 mostly coming from the random part of the error. In summary, GEOV1 products get the best performances with ground truth regardless the considered criterions.

Table 3: Statistics corresponding to the comparison with ground measurements for the several products considered. The terms $B$ and $S$ represent the mean and the standard deviation of the difference between the satellite products and ground references. Positive (Negative) Bias (B) indicates overestimation (underestimation) of satellite product regarding ground estimates.

\begin{tabular}{|c|c|c|c|c|c|c|c|c|c|c|}
\hline & \multicolumn{4}{|c|}{ LAI } & \multicolumn{4}{|c|}{ FAPAR } & \multicolumn{2}{|c|}{ FCOVER } \\
\hline & GEOV1 & CYCV31 & MODC5 & GLOV2 & GEOV1 & CYCV31 & MODC5 & JRC & GEOV1 & CYCV31 \\
\hline $\mathrm{N}$ & 48 & 45 & 49 & 27 & 42 & 39 & 42 & 40 & 65 & 60 \\
\hline RMSE & 0,744 & 1,075 & 0,92 & 1,392 & 0,078 & 0,128 & 0,108 & 0,226 & 0,095 & 0,177 \\
\hline B & $-0,104$ & $-0,36$ & $-0,263$ & $-1,046$ & 0,014 & $-0,042$ & 0,006 & $-0,163$ & 0,019 & $-0,121$ \\
\hline$S$ & 0,737 & 1,013 & 0,882 & 0,918 & 0,076 & 0,121 & 0,108 & 0,156 & 0,093 & 0,129 \\
\hline$\overline{\mathrm{R}^{2}}$ & 0,807 & 0,647 & 0,729 & 0,608 & 0,889 & 0,707 & 0,779 & 0,53 & 0,848 & 0,661 \\
\hline Slope & 0,85 & 0,59 & 0,69 & 0,46 & 0,91 & 0,69 & 0,77 & 0,54 & 0,98 & 0,59 \\
\hline Offset & 0,15 & 0,41 & 0,31 & 0,02 & 0,05 & 0,45 & 0,11 & 0,06 & 0,02 & 0,05 \\
\hline
\end{tabular}

\section{CONCLUSIONS}

A quality assessment of the first version of global biophysical products (LAI, FAPAR, FCOVER) developed in the framework of Geoland-2/BioPar, GEOV1, based on SPOT/VEGETATION observations and CYCV31 and MODC5 products, was performed over a limited time period (2003-2005). The validation methodology follows recommendations 
proposed in the context of the CEOS/WGCV LPV Sub-Group for validation of remote sensing vegetation products.

Results show that GEOV1 presents reliable and consistent global spatial distribution of retrievals with a dynamic range of LAI, FAPAR and FCOVER consistent with the expected values for these biophysical variables. It overcomes the positive bias of MODIS for very low LAI/FAPAR values, and the unrealistically strong temporal variations of MODIS products. Moreover, GEOV1 overcomes the early saturation observed in CYCLOPES LAI and the significant bias observed for the FCOVER variable. The intercomparison with other global vegetation products shows that GEOV1 and CYCV31 products are the most consistent, since they benefit from the same pre-processing of SPOT/VEGETATION data. The global consistency of GEOV1 LAI with MODC5 products is good in the majority of situations, with systematic differences within the user requirement in about $74 \%$ of the total global vegetated pixels. Systematic differences are mainly observed over Evergreen Broadleaf Forest where GEOV1 provides lower values, and over Broadleaf Crop regions (e.g., EEUU and Ukraine) and a large area of Siberia dominated by Needleleaf Forest where GEOV1 LAI/FAPAR values are higher. The comparison with GLOV2 shows the highest discrepancies with an overall tendency of GLOV2 to underestimate LAI retrievals. The comparison with the JRC-FAPAR shows large systematic uncertainties between both products. However, the uncertainties associated to different remote sensing estimates are larger over specific regions or land cover types. The highest discrepancies (systematic and overall) and lowest correlation between products are found for Evergreen Broadleaf Forest and Needleleaf Forest where contamination by cloud or snow limits the reliability of the reflectance values used as inputs in the algorithms.

The qualitative analysis of temporal profiles shows that GEOV1 products display consistent seasonal variations with those observed in the other four products. The GEOV1 temporal profiles are smooth, stable over natural areas, and with a realistic dynamic range from low to high values. They perform better than MODC5 that are shakier, GLOV2 that are less precise, and JRC-FAPAR that are less accurate.

Confrontation with ground measurements shows that GEOV1 products perform the best with ground reference maps (highest correlations, lowest systematic and overall errors). It shows also that the definition of GEOV1 LAI product agrees with the actual LAI definition when clumping at the shoot scale is not accounted for. Comparison with ground estimates of FAPAR shows similarly that the FAPAR definition of GEOV1 products agrees well with the nominal one.They provide a good agreement across the whole range of values, and only some underestimations of highest LAI are observed. The overall uncertainty (RMSE) is close to the required target accuracy ( 0.5 for LAI, and 0.05 for FAPAR). However, these results are limited by the number and representativeness of the ground data set regarding biomes and geographical areas.

In summary, GEOV1 products show good performances: a spatial distribution realistic over the globe,temporal profiles smooth and consistent from year to year, no systematic errors in the comparison with ground reference measurements with RMSE values close to the target accuracy. Their main limitation is the lack of spatio-temporal continuity, mainly over high latitudes and equatorial regions, as for the other global products. A limitation that could be partly solved with the GEOV2 gap filled version currently under validation. These results are highly significant and allow concluding that GEOV1 products have reached a validation stage level 2 according to CEOS LPV criteria, and are ready to be released to the user's community.

These validation results are, however, limited by the ground data set used to quantify the uncertainties attached to the satellite products. Currently, very few data is available over broadleaf evergreen and deciduous forests, and large regions around the world (e.g. Asia). Its representativeness could be improved by obtaining multi-temporal measurements over a larger number of sites which would sample better the various biomes around the world. Besides, the uncertainties associated to the ground reference data must be better quantified. It is thus 
expected to complement this GEOV1 validation exercise in the near future by increasing the period of study, and including new multi-temporal ground measurements.

\section{ACKNOWLEDGEMENTS}

Thanks are given to Sebastian Garrigues for providing us with the ground dataset compiled trough a collaboration fostered by the CEOS/WGCV LPV, as well as to all the peopleinvolved in the collection of the ground data used in this paper. Special thanks are also given to all the groups involved in the algorithm design and production of the global biophysical satellite products used in this study and to Nadine Gobron that provided us with extracts of the JRC FAPAR product over the sites considered in this study.

The research leading to these results has received funding from the European Community's Seventh Framework Program (FP7/2007-2013) under grant agreement ${ }^{\circ} 218795$. The GEOV1 products used in this study are the joint property of INRA and CNES under copyright geoland2. They are generated from SPOT VEGETATION data under copyright CNES and distributed by VITO.

\section{REFERENCES}

Abuelgasim, A. A., R. A. Fernandes, and S.G Leblanc, (2006). Evaluation of national and global LAI products derived from optical remote sensing instrument over Canada, IEEE Transactions on Geoscience and Remote Sensing, 44(7), pp 1872-1884.

Baret, F., J. Morissette, R. Fernandes, J. L. Champeaux, R. Myneni, J. Chen, et al. (2006). Evaluation of the representativeness of networks of sites for the global validation and intercomparison of land biophysical products.Proposition of the CEOS-BELMANIP.IEEE Transactions on Geoscience and Remote Sensing, 44, 1794-1803.

Baret, F.,Hagolle, O., Geiger, B., Bicheron, P., Miras, B., Huc, M., Berthelot, B., Weiss, M., Samain, O., Roujean, J.L. et al.,(2007). LAI, fAPAR and FCOVER CYCLOPES global products derived from VEGETATION. Part 1: Principles of the algorithm. Remote Sensing of Environment, 110: 275-286.

Baret, F, M. Weiss, R. Lacaze, F. Camacho, H. Makmara, P. Pacholczyk, and B. Smets, (2012). GeoV1: LAI, FAPAR Essential Climate Variables and FCOVER global time series capitalizing over existing products. Principles of development and production.Submitted to Remote Sensing of Environment.

Bartholome, E., and A. Belward (2005), GLC2000: A new approach to global land cover mapping from Earth Observation data, Int. J. Remote Sens., 26(9), 1959- 1977.

Butson, C. R., and R. A. Fernandes (2004), A consistency analysis of surface reflectance and leaf area index retrieval from overlapping clear-sky Landsat ETM+ imagery, Remote Sensing of environment, 89(3), 369-380.

Camacho, F., J. C. Jiménez-Muñoz, B. Martínez, P. Bicheron, R. Lacaze and M. Leroy (2006). Prototyping of FCOVER product over Africa based on existing CYCLOPES and JRC products for VGT4Africa. Proceedings of the $2^{\text {nd }}$ RAQRS symposium: 722-727. Torrent, 22-25 September 2006.

Camacho, F. and J. Cernicharo (2010). Low resolution (SPOT/VGT) Vegetation Variables (GEOV1) validation report.BP-RP-BP022, 82 pp(avalaible on-line athttp://www.geoland2.eu/portal/documents/CA80C881.html) 
Camacho, F., J. Cernicharo, J. García-Haro, A. Verger, J. Meliá (2010).Consistency assessment of FVC and LAI operational products over Africa.Proceedings of 3rd RAQRS, $27^{\text {th }}$ Sept. $-1^{\text {st }}$ Oct., Torrent, pp 694-699.

Camacho, F. and S. Lanjeri (2010). Geoland-2 Report on Ground Data Processing: Valencia Anchor Station_2008/09/09. G2-BP-RP-BP22-6, 24 pp.

Camacho, F. and I. Torralba (2010). Geoland-2 Report on Ground Data Processing: SAFARI 2000 Kalahari Transect Sites. G2-BP-RP-BP22-1, 35 pp.

Chen, J.M., et J. Cihlar (1995). Quantifying the effect of canopy architecture on optical measurements of leaf area index using two gap size method analysis, IEEE Transactions on Geoscience and Remote Sensing, 33(3), 777-787.

Chen, J. M. (1996). Optically-based methods for measuring seasonal variation in leaf area index of boreal conifer forests. Agricultural and Forest Meteorology, 80:135-163.

Chen, J.M., and S.G. Leblanc (1997).A 4-scale bi-directional reflection model based on canopy architecture. IEEE Transactions on Geoscience and Remote Sensing, 35, 1316-1337.

Chen, J.M., and S.G. Leblanc (2001).Multiple-scattering scheme useful for hyperspectral geometrical optical modelling. IEEE Transactions on Geoscience and Remote Sensing, 39, 1061-1071.

Chen, J.M., C. H. Menges and S. Leblanc (2005), Global derivation of the vegetation clumping index from multi-angular satellite data, Remote Sensing of Environment, 07, 447-457.

Chen, J.M., F. Deng and M. Chen (2006a), Locally adjusted cubic-spline capping for reconstructing seasonal trajectories of a satellite-derived surface parameter, IEEE transactions on Geoscience and Remote Sensing, 44(12), 3725-3736.

Chen, J.M., A. Govind, O. Sonnentag, Y. Zhang, A. Barr, and B. Amiro (2006b). Leaf Area Index measurements at Fluxnet-Canada forest sites, Agricultural and Forest Meteorology, 14(14), 257-268.

Cohen, W.B. and Justice, C.O., 1999. Validating MODIS terrestrial ecology products: linking in situ and satellite measurements. Remote Sensing of Environment,70: 1-3.

Cohen, W. B., T. K. Maiersperger, D. P. Turner, W. D. Ritts, D. Pflugmacher, R. E. Kennedy, A. A. Kirschbaum, S. W. Running, M. Costa, and S. T. Gower (2006). MODIS land cover and LAI Collection 4 product quality across nine sites in the western hemisphere, IEEE Trans. Geosci.Remote Sens., 44(7), 1843- 1858.

De Kauwe, M.G., M.I. Disney, T. Quaife, P. Lewis, and M. Williams (2011).An assessment of the MODIS collection 5 leaf area index product for a region of mixed coniferous forest. Remote Sensing of Environment 115: 767-780

Demarez, V.,S. Duthoit, F.Baret, M. Weiss and G. Dedieu (2008).Estimation of leaf area and clumping indexes of crops with hemispherical photographs.Agricultural and forest meteorology 148: $644-655$.

Deng, F., J.M. Chen, M. Chen and J. Pisek, (2006).Algorithm for global leaf area index retrieval using satellite imagery. IEEE Transactions on Geoscience and Remote Sensing, 44 (8): 22192229.

Fang, H., S. Wei, S. Liang (2012). Validation of MODIS and CYCLOPES LAI products using global field measurement data. Remote Sensing of Environment 119 (2012) 43-54 
Fernandes, R. A., C. Butson, S. Leblanc, and R. Latifovic (2003). A Landsat-5 TM and Landsat7 ETM+ based accuracy assessment of leaf area index products for Canada derived from SPOT4/VGT data, Canadian Journal of Remote Sensing, 29(2), 241-258.

Ganguly, S., A. Samanta, M. A. Schull, N. V. Shabanov, C. Milesic,R. R. Nemani, Y. Knyazikhin, Ranga B. Myneni (2008). Generating vegetation leaf area index Earth system data record from multiple sensors. Part 2: Implementation, analysis and validation. Remote Sensing of Environment 112 (2008) 4318-4332

Garcia-Haro, F.J., Camacho, F., \&Meliá, J. (2008).Vegetation Parameters Validation Report (VEGA VR), SAF/LAND/UV/VR_VEGA/2.1, January 2008, $91 \mathrm{pp}$ (available on-line at http://landsaf.meteo.pt).

Garrigues, S., Lacaze, R., Baret, F., Morisette, J. T., Weiss, M., Nickeson, J. E., et al., (2008a). Validation and Intercomparison of Global Leaf Area Index Products Derived From Remote Sensing Data. Journal of Geophysical Research, 113,G02028, doi: 10.1029/2007JG000635.

Garrigues, S., Shabanov, N., Swanson, K., Morisette, J., Baret, F., \&Myneni, R. (2008b). Intercomparison and sensitivity analysis of Leaf Area Index retrievals from LAI-2000, AccuPAR, and digital hemispherical photography over croplands, Agricultural and Forest Meteorology 148: 1193-1209.

GCOS, (2006).Systematic observation requirements for satellite-based products for climate.GCOS-107.WMO/TD No. 1338. September 2006. 103 pp (available online at http://www.wmo.int/pages/prog/gcos/Publications.htm).

GCOS, (2010).Implementation plan for the global observing system for climate in support of the UNFCCC (Updated 2010).GCOS-138 (GOOS-184, GTOS-76, WMO-TD/No. 1523). $\begin{array}{lllll}\text { August } & 2010 . & 183 & \text { pp } & \text { (available }\end{array}$ athttp://www.wmo.int/pages/prog/gcos/Publications.htm).

Gobron, N., Pinty, B., Verstraete, M. M. \&Govaerts Y. (1999). The MERIS Global Vegetation Index (MGVI): Description and Preliminary Application, International Journal of Remote Sensing, 20, pp. 1917-1927.

Gobron, N., Pinty, B., Verstraete, M. M., \&Widlowski, J.-L. (2000). Advanced spectral algorithm and new vegetation indices optimized for up coming sensors: Development, accuracy and applications, IEEE Trans. Geosci. Remote Sens., 38, 2489- 2505.

Gobron, N., B. Pinty, F. Me'lin, M. Taberner, \& M. M. Verstraete (2002).Sea Wide Field-ofView Sensor (SeaWiFS) - Level 2 land surface products-Algorithm theoretical basis document, EUR Rep. 20144 EN, Inst.for Environ.and Sustainability, Ispra, Italy.

Gobron, N., Pinty, B., Aussedat, O., Chen, J.M., Cohen, W.B., Fensholt, R., Gond, V., Huemmrich, K.F., Lavergne, T., Melin, F. et al., (2006). Evaluation of fraction of absorbed photosynthetically active radiation products for different canopy radiation transfer regimes: Methodology and results using JointResearchCenter products derived from SeaWiFS against ground-based estimations. Journal of Geophysical Research-Atmospheres, 111 (D13).

Govaerts, Y., M. M. Verstraete, B. Pinty, and N. Gobron (1999), Designing optimal spectral indices: A feasibility and proof of concept study, Int. J.Remote Sens., 20, 1853-1873.

Gower, S. T., C. J. Kucharik, and J. M. Norman (1999). Direct and indirect estimation of Leaf Area Index, FAPAR, and Net Primary Production of terrestrial ecosystems, Remote Sensing of Environment, 70(1), 29-51. 
Hagolle, O., A. Lobo, P. Maisongrande, F. Cabot, B. Duchemin, A. De Pereyra, (2004). Quality assessment and improvement of temporally composited products of remotely sensed imagery by combination of VEGETATION 1 and 2 images. Remote Sensing of Environment, 94(2): 172186.

Iiames, J. S., A. N. Pilant, and T. E. Lewis (2004). In-situ estimates of forest LAI for MODIS data validation, in Remote Sensing and GIS Accuracy Assessment, edited by R. S. Lunetta and J. G. Lyon, pp. 41-58, CRC, Boca Raton, Fla.

Jacquemoud, S.et F.Baret, (1990) PROSPECT: A model of leaf optical properties spectra, Remote Sensing of Environment, 34: 75-91.

Justice, C., Belward, A., Morisette, J., Lewis, P., Privette, J., \&Baret, F. (2000).Developments in the 'validation' of satellite sensor products for the study of the land surface. Int. J. Remote Sens., 21, 3383-3390.

Knyazikhin, Y., J. V. Martonchik, R. B. Myneni, D. J. Diner, and S. W. Running (1998). Synergetic algorithm for estimating vegetation canopy leaf area index and fraction of absorbed photosynthetically active radiation from MODIS and MISR data, Journal of Geophysical Research, 103(D24), 32,257-32,275.

Kobayashi, H., N. Delbart, R. Suzuki and K. Kushida (2010). A satellite-based method for monitoring seasonality in the overstory leaf area index of Siberian larch forestJournal of Geophysical Research, Vol. 115, G01002, 14 PP., 2010, doi:10.1029/2009JG000939

Lacaze, R. et al., (2009). BioPar User Requirements, http://www.gmes-geoland.info/projectdocumentation/user-requirements.html.

Law, B.E., A. Cescatti, D.D. Baldocchi (2001). Leaf area distribution and radiative transfer in open-canopy forests: Implications to mass and energy exchange. Tree Physiolology. 21:777787.

McCallum, I. et al., 2010. Comparison of four global FAPAR datasets over Northern Eurasia for the year 2000. Remote Sensing of Environment, 114(5): 941.

Martínez, B., F.J. García-Haro, F. Camacho, (2009). Derivation of high-resolution leaf area index maps in support of validation activities: Application to the cropland Barrax site. Agricultural and Forest Meteorology, 149:130-145.

Morisette, J.T., Baret, F., Privette, J.L., Myneni, R.B., Nickeson, J.E., Garrigues, S., Shabanov, N.V., Weiss, M., Fernandes, R., Leblanc, S.G. et al., (2006). Validation of global moderateresolution LAI products: a framework proposed within the CEOS land product validation subgroup. IEEE Trans. Geosc. Remote Sens., 44, 1804-1817

Myneni, R.B., Hoffman, S., Knyazikhin, Y., Privette, J.L., Glassy, J., Tian, Y., Wang, Y., Song, X., Zhang, Y., Smith, G.R. et al., (2002). Global products of vegetation leaf area and absorbed PAR from year one of MODIS data. Remote Sensing of Environment, 83: 214-231.

Pisek, J., and J.M. Chen (2007).Comparison and validation of MODIS and VEGETATION global LAI products over four BigFoot sites in North America. Remote Sensing of Environment 109, 81-94.

Privette, J. L., Y. Tian, G. Roberts, R. J. Scholes, Y. Wang, K. Caylor, and M. Mukelabai, (2004). Structural characterization and relationships in Kalahari woodlands and savannas. Global Ch. Biol., 10 (3): 281-291. 
Roujean, J.L., M. Leroy, and P.Y. Deschamps, (1992). A bidirectional reflectance model of the Earth's surface for the correction of remote sensing data. Journal of geophysical research, 97(D18): 20455-20468.

Shabanov, N. V., et al. (2005), Analysis and optimization of the MODIS Leaf Area Index algorithm retrievals over broadleaf forests, IEEE Trans.Geosci. Remote Sens., 43(8), 18551865 .

Steinberg, D.C., S.J. Goetz and E.J. Hyer (2006).Validation of MODIS FPAR Products in Boreal Forests of Alaska.IEEE Transactions on Geoscience and Remote Sensing, vol. 44, No. 7.

Tan, B., Hu, J., Huang, D., Yang, W., Zhang, P., Shabanov, N.V. et al., (2005). Assessment of the broadleaf crops leaf area index product from the TERRA MODIS instrument. Agricultural and ForestMeteorology, 135: 124-135.

Verger, A., (2008). Analisi comparativa d'algorismesoperacionalsd'estimacio de parametresbiofisics de la coberta vegetal ambteledeteccio, Universitat de Valencia, Valencia (Spain), 277 pp.

Verger, A., F. Camacho, F. J. García-Haro y J. Meliá (2009a). Prototyping of Land-SAF leaf area index algorithm with VEGETATION and MODIS data over Europe. Remote Sensing of Environment, doi:10.1016/j.rse.2009.06.009.

Verger, A., B. Martínez, F. Camacho and F. J. García-Haro (2009b).Accuracy assessment of fraction of vegetation cover and leaf area index estimates from pragmatic methods in a cropland area. International Journal of Remote Sensing, vol. 30. No 10: 2685-2704.

Verhoef, W. (1984), Light scattering by leaf layers with application to canopy reflectance modeling: The SAIL model, Remote Sensing of Environment ,16, 125- 141.

Vermote, E. F., D. Tanré, J. L. Deuzé, M. Herman, and J. L. Morcrette (1997), Second Simulation of the Satellite Signal in the Solar Spectrum, 6S: an overview, IEEE Transactions on Geoscience. Remote Sensing, 35(3), 675-686.

Verstraete, M. M., and B. Pinty (1996), Designing optimal spectral indices for remote sensing applications, IEEE Trans. Geosci.Remote Sens., 34, 1254- 1265.

Wang, Y., Woodcock, C.E., Buermann, W., Stenberg, P., Voipio, P., Smolander, H., et al. (2004). Evaluation of the MODIS LAI algorithm at a coniferous forest site in Finland, Remote Sensing of Environment, 91, 114-127.

Weiss, M., F. Baret, G. J. smith, I. Jonckheere, and P. Coppin (2004), Review of methods for insitu leaf area index (LAI) determination: partII. Estimation of LAI, errors and sampling, Agriculture and forest Meteorology, 121(1-2), 37-53.

Weiss, M., Baret, F., Garrigues, S., Lacaze, R. and Bicheron, P., (2007). LAI, fAPAR and FCOVER CYCLOPES global products derived from VEGETATION. part 2: Validation and comparison with MODIS Collection 4 products. Remote Sensing of Environment, 110: 317331.

Yang, W., Huang, D., Tan, B., Stroeve, J. C., Shabanov, N. V., Knyazikhin, Y., et al. (2006a). Analysis of leaf area index and fraction of PAR absorbed by vegetation products from the Terra MODIS sensor: 2000-2005. IEEE Transactions on Geoscience and Remote Sensing, 44(7):1829-1842.

Yang, W., Tang, B., Huang, D., Rautiainen, M., Shabanov, N.V, Wang, Y., et al., (2006b). MODIS Leaf Area Index products: from validation to algorithm improvements. IEEE Transactions on Geoscience and Remote Sensing, 44, 1829-1842. 


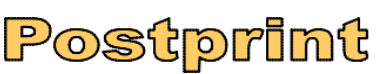

Version définitive du manuscrit publiée dans / Final version of the manuscript published in :

Remote Sensing of Environment (2013), Vol. 137, p. 310-329, DOI: 10.1016/j.rse.2013.02.030

Journal homepage: www.elsevier.com/locate/rse 